\title{
Bordelann et le Mésolithique insulaire en Bretagne
}

Bordelann and the Mesolithic of the Breton islands

Bordelann y el Mesolítico insular en Bretaña

\section{Grégor Marchand et Gérald Musch}

\section{OpenEdition}

\section{Journals}

Édition électronique

URL : http://journals.openedition.org/rao/2030

DOI : $10.4000 /$ rao.2030

ISBN : 978-2-7535-3432-2

ISSN : 1775-3732

\section{Éditeur}

Presses universitaires de Rennes

\section{Édition imprimée}

Date de publication : 25 décembre 2013

Pagination : 7-36

ISBN : 978-2-7535-3430-8

ISSN : 0767-709X

\section{Référence électronique}

Grégor Marchand et Gérald Musch, «Bordelann et le Mésolithique insulaire en Bretagne », Revue archéologique de l'Ouest [En ligne], 30 | 2013, mis en ligne le 25 décembre 2015, consulté le 03 décembre 2020. URL : http://journals.openedition.org/rao/2030 ; DOI : https://doi.org/10.4000/rao 2030

Ce document a été généré automatiquement le 3 décembre 2020.

Tous droits réservés 


\title{
Bordelann et le Mésolithique insulaire en Bretagne
}

\author{
Bordelann and the Mesolithic of the Breton islands \\ Bordelann y el Mesolítico insular en Bretaña
}

Grégor Marchand et Gérald Musch

\section{Le Mésolithique à Belle-Île-en-Mer}

\section{Une île dans son système économique littoral}

1 Les sondages menés à Bordelann sur la commune de Sauzon dans le Morbihan, sur l'île de Belle-île-en-Mer (fig. 1), s'intègrent à une problématique plus globale qui vise une meilleure compréhension du fonctionnement des sociétés mésolithiques. Dans cette approche, chaque site est conçu comme un point dans un réseau d'interactions dont on cherche à comprendre la nature. Toutes différences perçues, que ce soit dans l'implantation de l'habitat considéré, ses structures archéologiques, sa durée d'occupation ou la nature des activités réalisées peuvent recéler des informations sur la hiérarchie éventuelle entre les habitats, dans une optique fonctionnelle. Il s'agit ici plus particulièrement de comprendre la gestion des espaces littoraux par des peuples pratiquant une économie de chasse-cueillette fondée sur un certain degré de mobilité collective, avec comme contraintes supplémentaires la gestion stricte des ressources alimentaires et la navigation entre les îles. 
Figure 1 : Principaux sites tévieciens entre Odet et Vilaine. Figure 1 : Main teviecian sites betwenn Odet and Vilaine rivers.

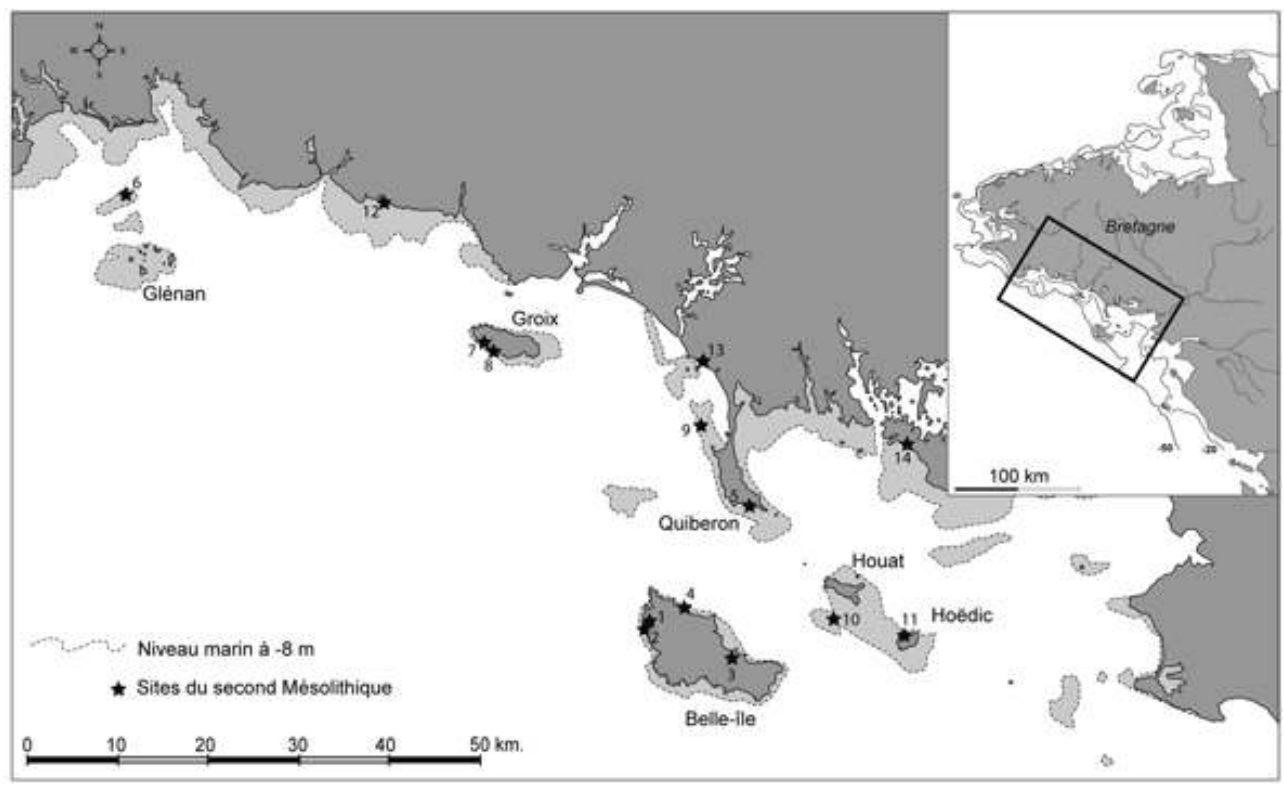

1 : Bordelann (Sauzon) ; 2 : Porh Lezoned (Sauzon) ; 3 : Kervin (Le Palais) ; 4 : pointe de Kerzo

(Sauzon) ; 5 : Beg-er-Vil (Quiberon) ; 6 : île aux Moutons (La Forest-Fouesnant) ; 7 : le Gorzed (Groix) ;

8: Quéhello (Groix) ; 9 : Téviec (Saint-Pierre-Quiberon) ; 10 : Melvan (Houat) ; 11 : Port-Neuf (Hoëdic) ;

12 : Pors-Bali (Moëlan-sur-Mer) ; 13 : Kerhillio (Erdeven) ; 14 : Kerjouanno (Arzon).

DAO G. Marchand.

2 Cette problématique est née progressivement au cours des dernières années, à mesure qu'émergeait l'hypothèse d'une opposition entre les zones littorales et l'intérieur du continent, à travers l'étude d'une large gamme de vestiges et de leurs conditions de découverte. Ainsi, l'absence sur la côte des roches de l'intérieur comme les phtanites, les ultramylonite, ou les cataclasites (Marchand, 2003, 2005 a et b, 2012; Marchand et Tsobgou Ahoupe, 2007), la forte ration de protéines d'origine marine dans les squelettes des nécropoles de Téviec et Hoëdic (Schulting et Richards, 2001) et les indices de saisonnalité grappillés lors de l'étude des proies (Tresset, 2002, 2005 ; Dupont, 2006 ; Dupont et al., 2009, 2010) plaident pour une certaine autonomie économique d'une bande littorale régulièrement parcourue dont la largeur reste encore à définir. Les recherches pluridisciplinaires qui y sont menées depuis une dizaine d'années ont permis de tracer les contours de ces économies dites "à large spectre" qui bénéficiaient d'une variété très étendue de ressources (Schulting et al., 2004 ; Dupont et al., 2009 ; Marchand, 2012). Mais quelle fut l'organisation des économies et des sociétés en ces lieux? Et quels rôles jouèrent les îles dans ces systèmes? L'insularité s'accompagna-t-elle de particularités dans l'outillage, dans la structure des productions matérielles ou bien encore dans les choix d'installation des campements ? Répondre à ces questions impose de considérer les liens de dépendance envers le continent et les moyens de navigation, et donc de questionner le degré de mobilité de ces populations à l'économie prédatrice.

\section{Belle-Île au Mésolithique}

3 La carte des fonds marins réalisée par le service hydrographique et océanographique de la Marine (SHOM) donne le sommet des dépôts sous-marins actuels et ses données 
doivent être complétées par les nombreux relevés sismiques à très haute résolution qui permettent de donner une idée du profil du socle rocheux et des dépôts sédimentaires qui le recouvrent (Menier, 2004; Menier et al., 2009, 2010; Sorrel et al., 2010). Ces données récentes laissent penser que Belle-Île fut un espace accessible depuis les îles de Houat et de Hoëdic lorsque les niveaux marins étaient inférieurs à vingt-cinq mètres sous l'actuel, mais que ce lien fut rompu avec un niveau marin à moins vingt mètres. D'après les courbes de remontée du niveau marin disponibles - anciennes désormais, mais il faut s'en satisfaire (Morzadec-Kerfourn, 1974 ; Pirrazoli, 1991) - de tels niveaux furent atteints lors de la seconde moitié du VIII ${ }^{e}$ millénaire avant notre ère. L'ensemble de terres formé par ces îles bordait au sud l'embouchure de la Paléo-Vilaine qui, à l'époque, était un large estuaire à l'emplacement de la baie de Quiberon. La ligne de partage des eaux entre cette grande vallée et un autre système fluvial (dit de l'Artimon) courait entre Houat et Piriac-sur-Mer, formant un isthme relativement étroit (Menier et al., 2010). La question de l'immersion de ce lien terrestre et, donc, de l'insularité de l'ensemble insulaire Houat-Hoëdic reste ouverte : il semble que ce pont qui reliait l'île de Houat et la presqu'île guérandaise fusse déjà coupé lorsque le niveau marin était inférieur de vingt-cinq mètres à l'actuel. Cela serait donc intervenu un peu avant la séparation entre Belle-Île et la grande île Houat-Hoëdic, soit au début du $\mathrm{VIII}^{\mathrm{e}}$ millénaire avant notre ère, assurément donc avant les occupations mésolithiques de Bordelann ou de Hoëdic.

D'après la courbe de M.-T. Morzadec-Kerfourn, un stationnement marin vers -12/-13 mètres sous l'actuel serait observé dans la seconde moitié du VII ${ }^{\mathrm{e}}$ millénaire avant notre ère, qui pourrait correspondre au niveau marin contemporain du début du second Mésolithique (Téviecien dans la région), avec de notables transformations du contour d'îles basses comme Hoëdic, mais presqu'aucun changement pour Belle-île ceinte de hautes falaises. Toutes ces estimations restent très hypothétiques, d'autant que les dates par le radiocarbone actuellement acceptées sont rares et réalisées sur coquilles marines, sans connaissance de la valeur locale de la variation de l'effet réservoir (par exemple dans Sorrel et al., 2010), pourtant disponible dans la bibliographie (Marchand et al., 2009), mais aussi parce qu'il est difficile de modéliser la vitesse de déblaiement des dépôts périglaciaires.

5 L'insularité est un paramètre géographique fort original lorsque l'on souhaite travailler sur l'occupation du territoire au Mésolithique ; il vient s'ajouter à d'autres paramètres naturels fondamentaux sur cette île. Ainsi, le socle constitué pour l'essentiel de schistes et de micaschistes conduit à une certaine uniformité des formes de paysage. Ce vaste plateau assez monotone est cependant entaillé par de nombreux vallons raccordés ou non aux plages actuelles, qui abritent des écosystèmes contrastés liés à des zones humides. Sur un espace aussi vaste, il est tout à fait possible d'envisager l'existence de grands mammifères, comme les chevreuils, les cerfs et les sangliers (Marchand, 2012), même si leur extinction, non datée, vient nous rappeler qu'aucune résilience n'est possible dans de tels milieux: l'homme qui a abattu le dernier chevreuil a commis l'irréparable! Cette île, comme d'ailleurs les autres sur la façade atlantique, n'était pas un espace riche en ressources terrestres, ni d'un point de vue minéral, ni d'un point de vue animal.

6 Ces grands paramètres écologiques et géographiques étant posés, il faut maintenant constater que Belle-Île a été occupée au Mésolithique et de manière non anecdotique : déjà en 1988 et 1989, des prospections menées par M. Batt et O. Kayser (1989) sur les 
quatre communes de l'île avait montré tout le potentiel de cette aire géographique. Deux sites mésolithiques furent alors repérés en sommet de falaise, Bouladew (aujourd'hui Bagueneres) à Bangor et Douar Port Yzed à Sauzon. Les prospections de plus longue durée de G. Musch (Audouard et al., 2010), mais aussi celles de P. Crevat et de J.-P. Huot, sont venues accroître ces premières données (fig. 2). Pour le premier Mésolithique (IX et VIII millénaires avant notre ère), on peut signaler l'abri sous roche de Valenpaul à Locmaria, mais aussi, sur la même commune, la pointe de Bornor sur la côte sauvage, au sommet des plus hautes falaises de l'île. Installé dans un contexte aussi exposé aux éléments, Bagueneres à Bangor peut également être attribué à cette période avec, comme armatures emblématiques, des pointes et des triangles. Belle-île est, à ce moment-là, encore continentale : c'est un haut plateau dominant de plus de quatrevingts mètres l'embouchure de la Paléo-Vilaine qui coulait sur son flanc nord, un peu à la manière d'une «mesa ». Nul doute que la position dominante fut déterminante dans ces choix d'implantation! Quant aux activités qui s'y déroulèrent...

Figure 2 : Carte des sites mésolithiques de Belle-Île (Morbihan). Figure 2 : Mesolithic sites on Belle-Île Island (Morbihan).

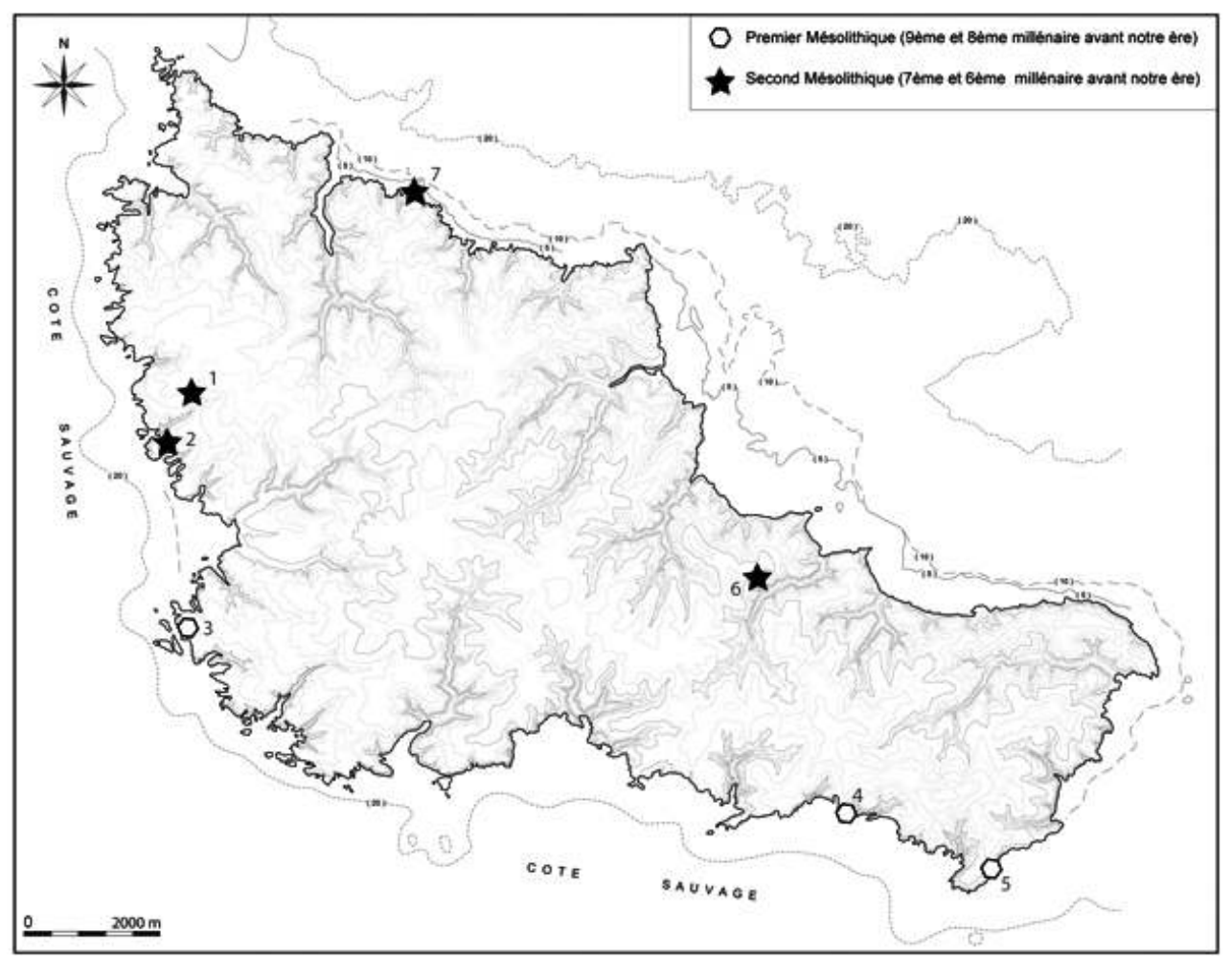

1 : Bordelann ; 2 : Porh Lezoned ; 3 : Bagueneres ; 4 : Bornor ; 5 : Valenpaul ; 6 : Kervin ; 7 : pointe de Kerzo.

DAO L. Quesnel, complétée par G. Marchand.

7 Au second Mésolithique ( $\mathrm{VII}^{\mathrm{e}}$ et $\mathrm{VI}^{\mathrm{e}}$ millénaires), période connue pour ses industries à lames régulières et à armatures géométriques trapézoïdales, quatre sites supplémentaires sont signalés, dont trois sur la commune de Sauzon: la pointe de Kerzo, Bordelann et Porh Lezoned (ou « Port des Sonnettes »). Le dernier, Kervin, a été découvert sur la commune du Palais et le mobilier mésolithique est amplement mélangé à celui, plus important, des occupations néolithiques ultérieures. Il y a donc des campements sur les deux côtes, mais les sites homogènes avec de grands 
assemblages lithiques sont installés sur la côte " extérieure ", face au large. Kervin et Bordelann sont les sites les plus à l'intérieur de l'île, même si on peut encore qualifier le second de péri-côtier par ses conditions naturelles. La facilité des prospections sur le sentier littoral est peut-être en cause dans l'état des connaissances, mais cela resterait à démontrer par de plus amples prospections et des sondages dans le reste de l'île.

Belle-Île est une sorte de "jachère archéologique ", puisqu'aucune fouille autorisée n'y a été conduite avant nos sondages de 2011, un oubli incompréhensible si l'on considère sa position centrale pour le littoral du Morbihan. Dominant l'horizon et fermant le "Mor Bras », ce vaste territoire est un évident point d'appui pour des groupes humains, qu'ils soient mobiles comme les chasseurs-cueilleurs du Mésolithique ou davantage sédentaires comme les occupants ultérieurs. Sur cette grande pénéplaine formée de roches volcano-sédimentaires relativement meubles surélevées par les mouvements tectoniques (Sélosse, 2000), l'absence de roches siliceuses taillables, hors des quartz, est particulièrement notable. La qualité de ces roches filoniennes est variable, mais reste médiocre pour l'obtention de tranchants fins. Par ailleurs, les plages actuelles n'offrent de petits galets de silex que de manière parcimonieuse.

\section{Archéographie du site de Bordelann}

\section{Description de la parcelle}

Le site de Bordelann se trouve à l'ouest de l'île sur la commune de Sauzon, à six cents mètres en retrait de falaises hautes à cet endroit de vingt-cinq mètres (fig. 1 et 2). Les fonds marins plongent rapidement et même en diminuant d'une quinzaine de mètres le niveau de l'océan, la ligne de côte ne s'éloigne que de deux cents mètres. Les recherches de géomorphologie sous-marines ont d'ailleurs montré l'existence de quatre platiers autour de Belle-Île : à $-8 /-10$ mètres, $-20 /-25$ mètres, -30 mètres et -35 mètres qui correspondraient à des stationnements marins relativement proches des falaises actuelles sur la côte ouest (Menier, 2004, p. 77).

Le substrat du site est formé des micaschistes qui composent l'essentiel des roches de cette île. Les vestiges sont répandus au milieu d'une pente régulièrement inclinée en direction du sud, avec une déclivité de 5,70 mètres pour 100 mètres, à des altitudes comprises autour de $35 \mathrm{~m}$ NGF. La parcelle explorée est bordée à l'est (vers une source) et au sud (vers un vallon) par des déclivités très marquées; la première de deux à trois mètres, la seconde - presque une falaise - de plus de six mètres de haut. Elle occupe le flanc septentrional d'un vallon qui mène au "port de Kerlédan », une anse naturelle parée d'une plage de galets de quartz. Ce vallon connecté à l'océan est particulièrement humide et il est engorgé de sédiments; saules, fougères, prunelliers et ajoncs sont présents sur ses flancs, tandis qu'une prairie occupe son centre. L'emplacement du site préhistorique serait relativement anodin s'il n'y avait une source encore très active immédiatement à l'est, dans un court thalweg orthogonal au vallon de Kerlédan, dont la tête commence à hauteur du village de Bordelann. On notera que les occupations se sont faites, non pas autour du point d'eau, mais à soixante-dix mètres à l'ouest, sur une pente régulière, hors de toute accroche topographique sensible dans le paysage. Si le champ actuel mesure 6300 mètres carrés, la zone de densité maximale des pièces archéologiques couvre environ 2200 mètres carrés, avec une concentration 
particulière de 600 mètres carrés dans une très légère cuvette naturelle sur la pente (lignes hachurées sur la figure 3).

Figure 3 : Plan du site de Bordelann (Sauzon), avec indication de l'emplacement des sondages réalisés en 2011 et des carottages de 2009.

Figure 3 : Map of the excavations and of the core drillings on the Mesolithic site of Bordelann (Sauzon).

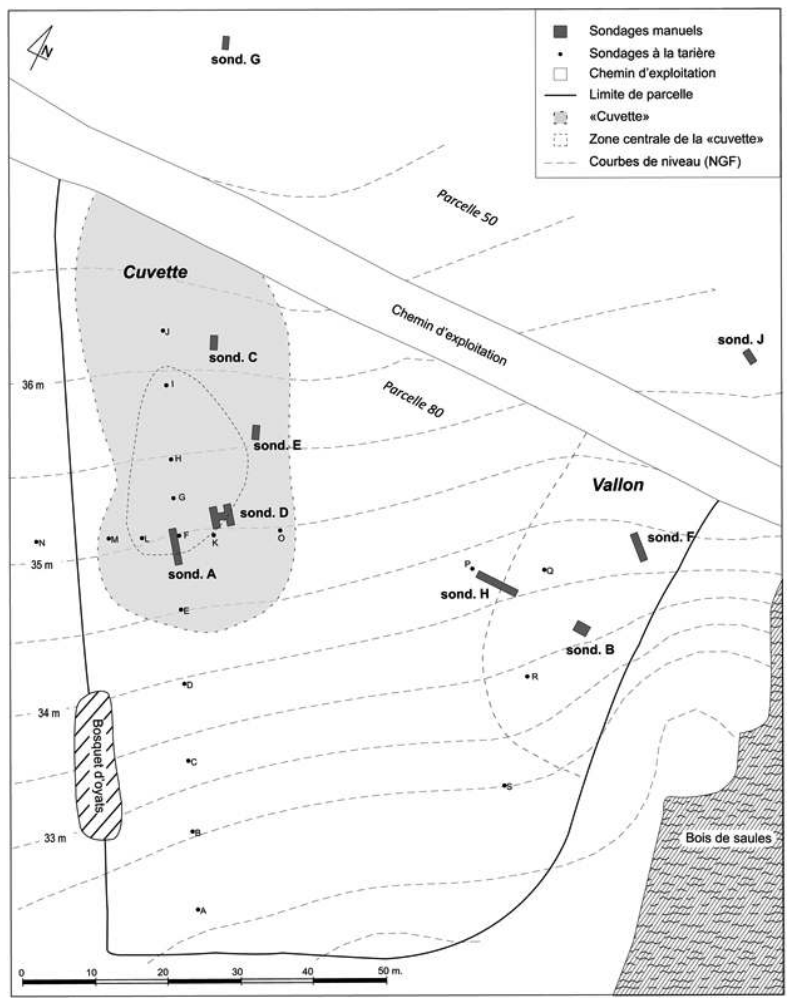

Relevé et DAO G. Marchand.

\section{Méthode d'investigation}

11 En 2009, dix-neuf carottes sédimentaires agencées en deux lignes orthogonales avaient été obtenues avec une carotteuse à main, de sept centimètres de diamètre (fig. 3). Elles avaient permis d'obtenir une vision qui s'est avérée très précise de l'état sédimentaire $\mathrm{du}$ site et nous désignaient une sorte de cuvette très peu imprimée comme zone d'intervention préférentielle si l'on entendait découvrir d'éventuels niveaux en place sous le labour. L'abondance de mobilier à cet endroit pouvait traduire soit la concentration de pièces par les colluvions agricoles à la faveur d'une très légère concavité du substrat, soit une destruction accrue du niveau archéologique. Mais la rareté des fragments de micaschiste à cet endroit, contrairement au reste de la parcelle, nous donnait à penser que la première hypothèse était la plus probable et que cette zone d'une trentaine de mètres de long et d'une vingtaine de large pouvait receler des surprises.

En mai 2011, neuf sondages manuels furent réalisés pour une surface totale de trentedeux mètres carrés. Les sondages $\mathrm{A}$ et $\mathrm{D}$ (fig. 4) ont concerné directement cette cuvette ; les sondages $\mathrm{C}$ et $\mathrm{E}$ furent creusés plus haut sur la pente mais également dans la zone de concentration de silex taillés. De l'autre côté du chemin, en haut de la pente, nous avons implanté le sondage $\mathrm{G}$, pour tenter de comprendre la dynamique colluviale. 
Ces cinq sondages totalisaient une surface de dix-huit mètres carrés dont la fouille fut menée jusqu'au substrat. Le vallon a été examiné par les sondages $B$ et $F$; le sondage $H$ à l'ouest était destiné à décrire la «naissance " de ce vallon et à trouver d'éventuels niveaux préhistoriques piégés sous des sédiments. Le sondage J a été installé dans l'axe de ce vallon mais de l'autre côté du chemin d'exploitation. Ces quatre sondages totalisaient quatorze mètres carrés, dont 11,5 furent fouillés intégralement (une banquette a été laissée dans le sondage B). Les pièces archéologiques ont été relevées par mètre carré et par unité stratigraphique.

Figure 4 : Le sondage $D$ à hauteur du site mésolithique (la « cuvette) en cours de fouille, vu du nordouest.

Figure 4 : Excavation $D$ in the mesolithic part of the site and excavation $F$ on the left of the picture.

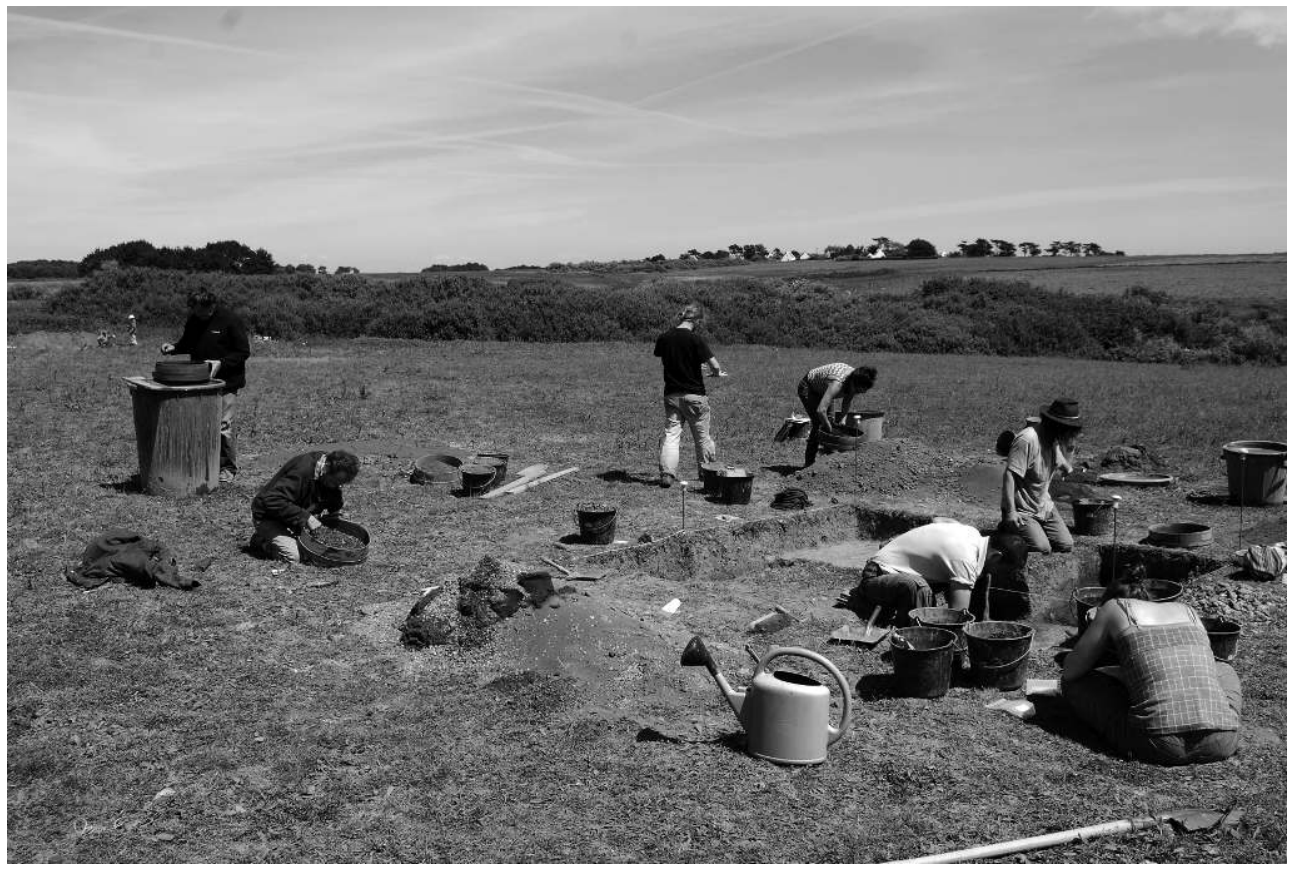

Le bosquet d'arbres en arrière-plan entoure la source pérenne. Le sondage F apparaît à gauche de l'image.

Cliché G. Marchand.

13 Il convient de bien distinguer les sondages où fut mis en place un tamisage à l'eau systématique (tamis à maille de $1 \mathrm{~mm}$ de côté), comme les sondages $\mathrm{D}$ et $\mathrm{E}$, des autres où seul un ramassage à vue fut effectué $(\mathrm{A}, \mathrm{C}, \mathrm{G}$ et $\mathrm{H})$. Dans le sondage $\mathrm{D}$, on enregistre par exemple des concentrations de 430 pièces au mètre carré (136 sans les esquilles); dans le sondage $\mathrm{E}$, ce sont 386 pièces au mètre carré. Avec une puissance sédimentaire équivalente (épaisseur de moins de 0,50 mètre de limon, de la surface au rocher), il n'y a que vingt-sept pièces au mètre carré dans le sondage $\mathrm{A}$ ou dix-huit dans le sondage $\mathrm{C}$. Inutile de préciser que seuls les premiers ont un intérêt pour l'étude de la culture matérielle. Labours et colluvions agricoles sous-jacentes sont des niveaux très agressifs pour les restes organiques, comme en témoigne l'absence de charbons dans les sédiments. Il n'en va pas de même du beau et épais niveau noir (US 3) du vallon, très riche en matière organique. Bien évidemment, ni les conditions sédimentaires des premiers, ni l'intérêt scientifique du second ne justifiaient de datations par le radiocarbone. 


\section{Stratigraphie et dynamique sédimentaire}

\section{La pente et la « cuvette »}

La dynamique colluviale est nette, tant ancienne que récente, sur toute la zone où furent récoltés les vestiges mésolithiques (fig. 5). Sous un niveau de labours récents d'une épaisseur de 20 à 25 centimètres (US 1), gisait un niveau de limons riche en micro-fragments de schistes et de quartz qui était épais d'une dizaine de centimètres (US 2). À sa base, et seulement dans certains sondages (A et C), apparaissait une autre unité stratigraphique enrichie en argile, de quelques centimètres d'épaisseur (US 3) ; au sommet de cette dernière, un lit de gravillons a été observé dans le sondage $\mathrm{A}$, qui pourrait signer une ancienne troncature sédimentaire. Le substrat atteint partout est un micaschiste à nombreuses veines de quartz, sans irrégularités particulières. Seule structure identifiée, un fossé étroit dans le sondage D s'imprimait dans le substrat sur seize centimètres de profondeur avec un remplissage de limons bruns clairs (fait 102). Ses bords étaient inclinés et son fond était plat, ce qui laisse penser à un ancien fossé de parcellaire d'axe nord-sud.

Figure 5 : Coupes des sondages réalisés dans la « cuvette " (sondages A, C, D et E).

Figure 5 : Sections of the excavations on the slope $(A, C, D$ and $E)$.

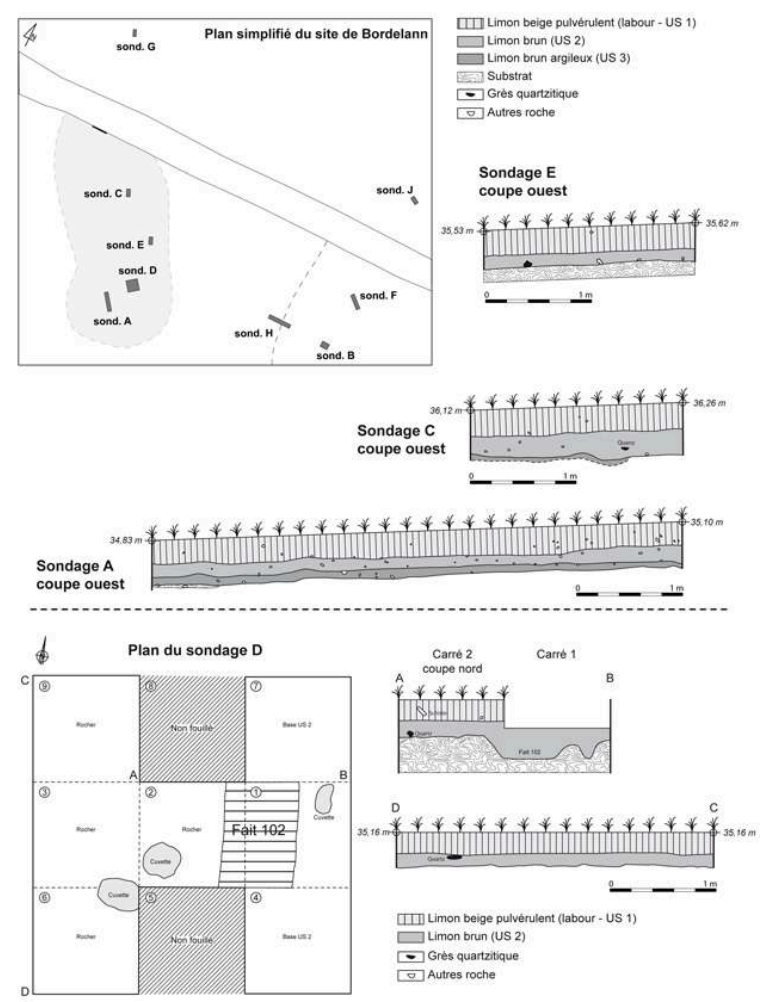

Relevés G. Marchand, L. Audouard et E. Werthe ; DAO L. Quesnel.

On constate donc que, contrairement aux hypothèses initiales, le centre de la cuvette n'a pas livré de niveau infra-labour plus développé qu'ailleurs. La richesse en mobilier archéologique ne s'est en revanche pas démentie. Grâce aux tamisages à l'eau, 3011 silex taillés et 202 fragments de quartz ont été recueillis dans les sept mètres carrés du sondage D. Outillage en silex et débitage sont clairement attribuables au Téviecien, notamment les dix-sept armatures entières ou fragmentées recensées. Il y 
avait également un tesson de petites dimensions (moins de vingt millimètres de long, dix millimètres d'épaisseur) dès la base de l'US 2, dans les failles du micaschiste pulvérulent. De même que trois autres découverts dans l'US 1 , il pourrait être néolithique ou protohistorique. Une molette en quartz filonien de forme circulaire a également été découverte dans le labour. Elle mesurait 71,8 millimètres de diamètre pour une épaisseur de 44,1 millimètres. Ses bords écrasés tout autour de la pièce affectaient une forme en biseau. Son attribution au Mésolithique est impossible et il faut y voir un outil néolithique ou protohistorique, en lien peut-être avec les quatre tessons. Les US 1 et 2 étaient contaminées également par des vestiges plus récents: ardoises très fragmentées, morceaux de verre translucide et un clou rouillé.

Il est impossible de dater avec précision ces dépôts sédimentaires remaniés, mais on notera que l'essentiel des trouvailles est sans conteste attribuable au Téviecien, tant dans l'US 1 que dans l'US 2 ('US 3 est anecdotique). Cependant, dans les sondages C, D et $\mathrm{E}$, des petits tessons à dégraissants sableux grossiers gisaient sous le reste du mobilier du Mésolithique, à la base de l'US 2 voire au contact du rocher (1 dans le C et le D, 3 dans le E). Leurs faibles dimensions et leurs états de surface dégradés rendent difficile une estimation chrono-culturelle correcte. Ils sont, quoi qu'il en soit, en faible nombre (huit en tout dans les sondages de la "cuvette ») et ne peuvent se comparer en quantité aux milliers de silex taillés. Parmi ceux-ci, tant dans les sondages qu'en surface, il est difficile d'identifier beaucoup d'objets du Néolithique : on mentionnera avec beaucoup de réserve certaines bitroncatures symétriques allongées (cf. infra), mais il y a un seul fragment de grattoir et aucun perçoir fusiforme si caractéristique du Néolithique régional en zone péri-côtière, que ce soit dans les sondages ou dans la collection de surface. On constate que même dans cette dernière, la production par percussion bipolaire sur enclume, caractéristique du Néolithique récent et final, est peu développée. L'hypothèse de tessons protohistoriques est donc plus probable que celle de vestiges néolithiques.

Il nous semble plus pertinent de réfléchir à cette sorte d'inversion stratigraphique qui nous dit quelque chose concernant l'histoire sédimentaire de ce site. Il est possible en effet que le mobilier du Mésolithique provienne de plus haut sur la pente et ait recouvert un niveau protohistorique très peu riche et déjà très altéré (tableau 1). Mais l'abondance des esquilles et les altérations modérées de ces pièces lithiques ne plaident pas pour un long déplacement, peut-être seulement quelques mètres. Une autre hypothèse serait que la céramique existait également dans l'US 1 en plus grand nombre, mais que l'acidité des sols en est venue à bout. Quoi qu'il en soit, nous sommes amenés à conclure à un large bouleversement de ces niveaux archéologiques, sous une dynamique colluviale évidente.

Tableau 1 : Objets autre que le silex ou le quartz taillés découverts dans les sondages de 2011. Table 1 : Artifacts other than flint or worked quartz found in the trenches of 2011

\begin{tabular}{|l|l|l|l|l|l|l|l|l|l|l|}
\hline Type de pièce & & A & B & C & D & E & F & H & J & Total \\
\hline Galet de quartz brut & Entier & 2 & & 1 & 2 & & & & 5 \\
\hline & Fragment & & & 1 & 1 & & & & 2 \\
\hline Macro-outil & Entier & 1 & 1 & 1 & 2 & & 2 & & 7 \\
\hline
\end{tabular}




\begin{tabular}{|l|l|l|l|l|l|l|l|l|l|l|}
\hline & Fragment & & 1 & & 2 & 2 & & & 5 \\
\hline Éclat grès/quartzite & & & & 1 & 6 & 2 & & & 9 \\
\hline Tesson & Grossier & & 8 & 1 & 4 & 3 & 10 & & 26 \\
\hline & Antique & & & & & & 10 & & 10 \\
\hline & Récent & 4 & 8 & & & & & & 1 & 12 \\
\hline Ardoise & Autre & 1 & & & & 1 & 8 & 2 & 9 & 21 \\
\hline Verre & & 1 & & & 26 & 11 & & 1 & 39 \\
\hline Clou en fer & & & & & 19 & 2 & 1 & & 22 \\
\hline
\end{tabular}

Où habitaient les hommes et les femmes du Mésolithique? Le déplacement des sédiments sur une pente pourtant faible a été évidemment accentué par l'agriculture, mais on ne peut écarter l'hypothèse d'atteintes antérieures, d'origine totalement naturelle. Au hasard d'un incendie et de la dégradation du couvert végétal, une déstabilisation des sols a pu intervenir. Il est probable que les pièces ne venaient pas de très loin, car au-delà du chemin il n'y a aucun indice préhistorique et les sédiments sont fort peu épais (sondage $G$ ). Mais cette cuvette légère, à peine perceptible dans le paysage, aura probablement été suffisante pour concentrer le mobilier, perturbant définitivement la compréhension spatiale du site. Le lecteur comprendra aisément pourquoi, à l'issue de ces seize mètres carrés de fouille dans la cuvette, nous n'estimons pas nécessaire d'y continuer des investigations certes très riches en mobilier, mais aux résultats pour le moins redondants.

\section{Le vallon}

Toute différente est la situation sur les bords du vallon sud-est, à proximité de la source, où fut identifiée une belle succession stratigraphique sur 1,30 mètre, dans deux sondages (B et F) (fig. 6 et 7). Elle n'a dû sa protection qu'à la construction d'un talus qui a retenu les colluvions agricoles qui supportent l'actuel niveau de labour. Ce dernier est épais ici de 15 à 20 centimètres et il est constitué d'un limon gris enrobant quelques plaquettes de micaschiste et des quartz non roulés (US 1). Il surmonte un niveau de limon brun clair et de micro-fragments de schiste et de quartz, très compact, épais de 30 à 35 centimètres (US 2). Il faut noter que la base de cette US, interprétée comme un ensemble de colluvions agricoles récentes bloquées par le talus, est horizontale, ce qui n'est le cas ni de son sommet, ni de la surface actuelle. L'US 3 qui gît dessous est un limon peu argileux de teinte brun foncé à noir, peu compact, à nombreux charbons de bois, avec quelques plaquettes de micaschiste éparses. Épais de cinquante centimètres en moyenne, ce niveau est marqué par des trainées verticales noires dans ses vingt derniers centimètres (manganèse), liées à la forte hydromorphie du milieu. La rupture sédimentaire est nette avec le niveau inférieur, qui se matérialise par un cailloutis de quartz à l'aspect bosselé, mal roulés, enrobés dans une matrice 
sablo-argileuse peu abondante (US 4). On observe une remontée progressive du niveau d'eau après quelques heures de fouille, qui submerge totalement l'US 4 et baigne la base de l'US 3.

Figure 6 : Coupe nord-ouest du sondage B, montrant l'épais niveau organique sous les colluvions récentes.

Figure 6 : North-western section of the excavation $B$, with the thick organic layer under the colluviums.

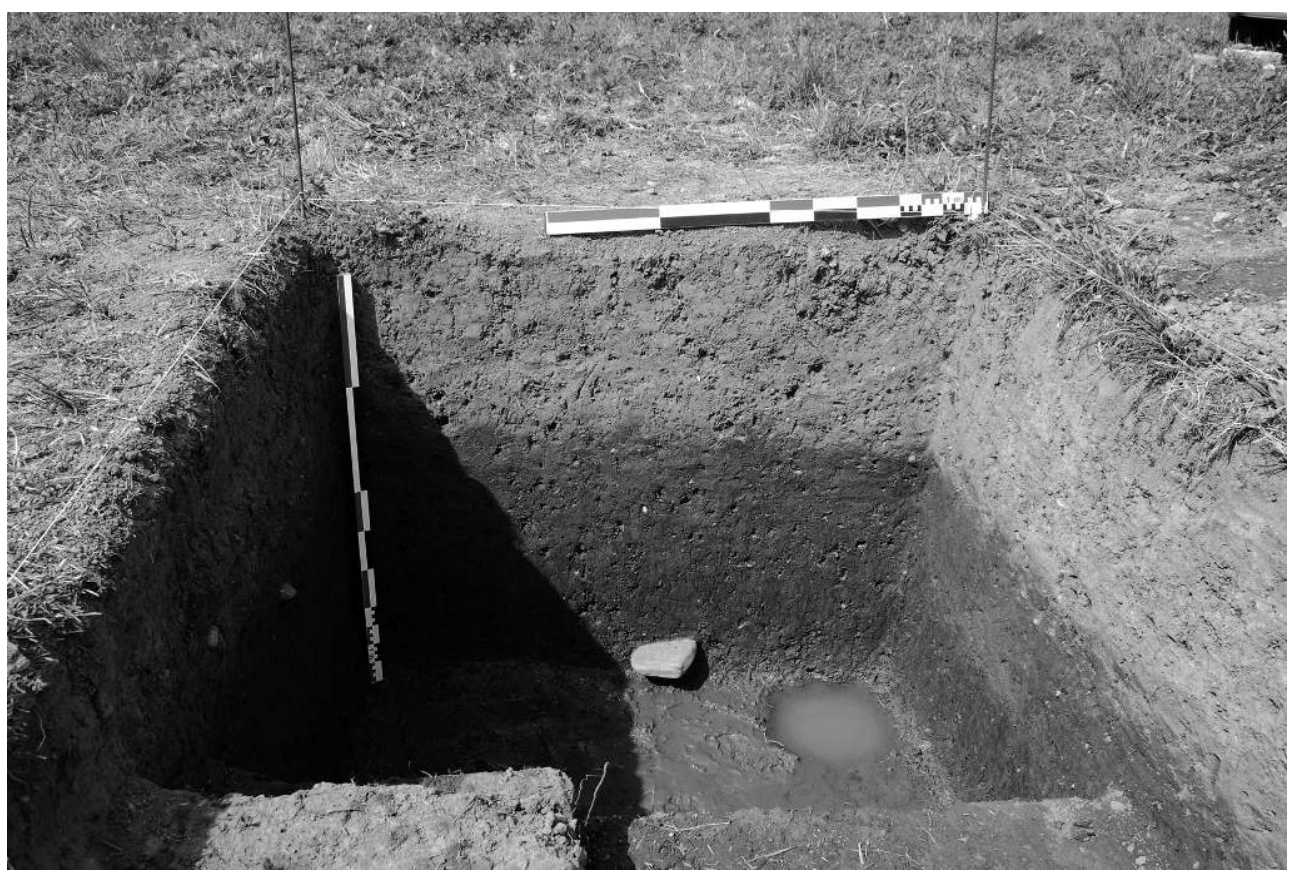

Le galet de grès/quartzite à la base ne porte pas de traces d'usage, mais son arrivée est due nécessairement à une action humaine. Le niveau de graviers commence à la base du niveau noir. The sandstone / quartzite pebble lies on the prehistoric level.

Cliché G. Marchand. 
Figure 7 :Coupes des sondages réalisés dans le vallon (sondages $B, F$ et $H$ ). Figure 7 : Sections of the excavations in the valley near the well $(B, F$ and $E)$.

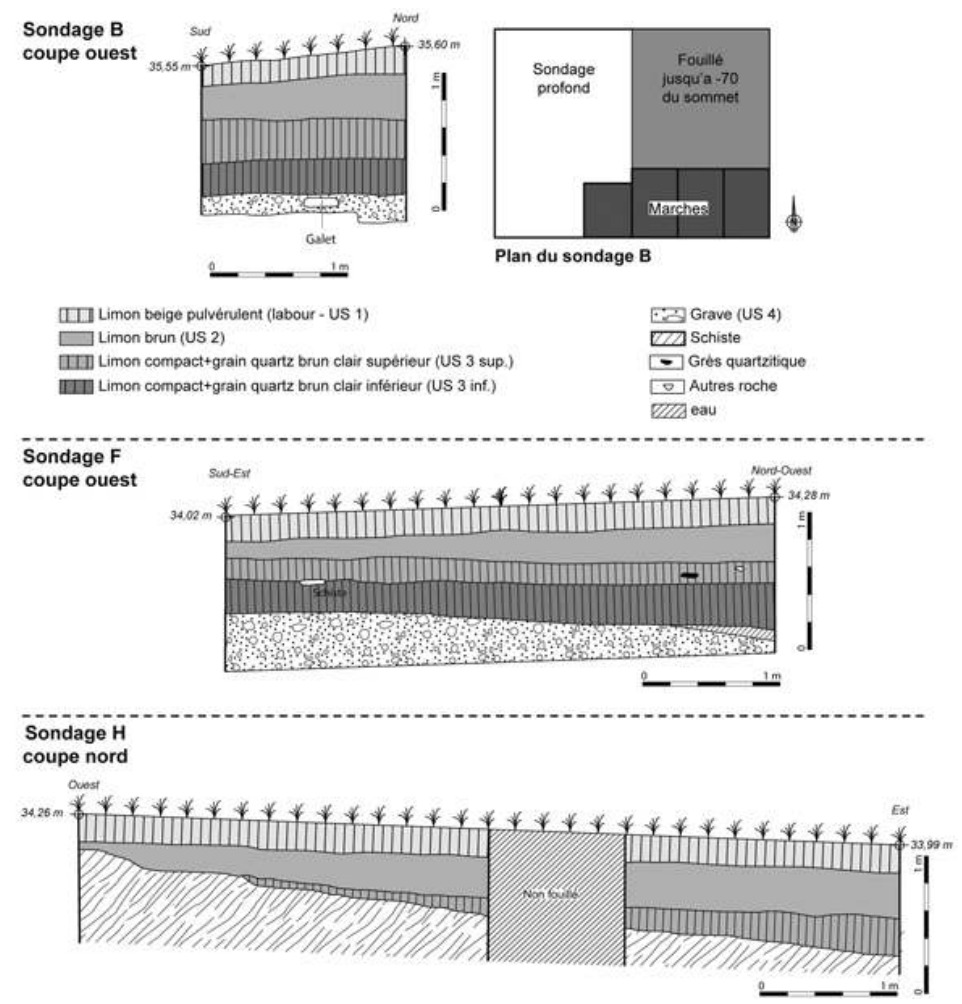

Relevés G. Marchand; DAO L. Quesnel.

Du mobilier archéologique est présent dans les trois unités qui surmontent le cailloutis. Dans les deux supérieures, il s'agit de rares tessons d'âges historiques mêlés à de rares silex mésolithiques; on note aussi dans l'US 2 du sondage B un fragment de meule en granite à double face très usée, au profil semi-ovalaire, épais de 35 millimètres. L'US 3 est nettement mieux constituée et révèle des successions d'occupations depuis le Mésolithique, à l'interface avec le gravier de l'US 4 (un nucléus lamellaire dans le sondage F), jusqu'à l'époque antique au sommet, en passant par des tessons à surface noire et des plaquettes de micaschiste chauffées et fortement rougies en milieu de couche. Malgré nos tests de tamisage à l'eau, il est clair que l'on ne dispose pas, hélas, d'un niveau mésolithique constitué à la base de l'US 3, alors que les conditions sédimentaires s'y prêtaient volontiers. Il en va de même pour les périodes ultérieures, probablement néolithiques, protohistoriques et antiques, dont les vestiges gisaient à plat dans la couche noire, sans que leur faible concentration n'incite l'archéologue à y développer une stratégie ambitieuse de recherche. La fouille de ce niveau en place ne se justifierait que dans la perspective plus vaste de l'exploration d'un habitat à proximité, qui n'a pour l'instant pas été repéré. Toute différente est l'origine du cailloutis basal agglomérant des fragments de quartz mal roulés et bosselés, qui surmonte d'au moins vingt centimètres le micaschiste altéré et nappe certainement tout le vallon. Son origine périglaciaire semble évidente et cela nous donne à imaginer l'aspect dénudé que devait revêtir le vaste plateau de Belle-Île durant le Pléniglaciaire, avec ses flancs de vallon exposés à nu et ravinés par l'érosion. 


\section{L'industrie lithique}

\section{Les états de surface}

21 Le tamisage systématique à l'eau et au tamis à maille fine des sondages $\mathrm{D}$ et $\mathrm{E}$ a livré $95 \%$ du mobilier lithique recueilli durant cette opération, d'où procède la vision la plus juste des chaînes opératoires de débitage (tableau 2). Cela démontre encore une fois la nécessité impérieuse de cette méthode d'approche, surtout dans une région où la pénurie de matériaux siliceux à grain fin a souvent poussé les tailleurs à réduire les dimensions des supports de leurs outils. Fouiller un site paléolithique, mésolithique ou néolithique avec un simple ramassage à vue, comme certains opérateurs pressés acceptent de le faire, nous prive d'informations essentielles. Sans tamisage, impossible de démontrer dans un site du second Mésolithique l'absence d'hyper-microlithes et donc de comprendre le lien ou la rupture avec les périodes antérieures où ces petits éléments abondaient. Et plus généralement, l'absence de cette méthode ne permet pas non plus de comprendre en détail les séquences de plein débitage, dont les produits sont toujours les plus menus et représentent pourtant les vrais objectifs des tailleurs : que l'on compare seulement les proportions de pièces recueillies dans les sondages A et $\mathrm{D}$, pourtant proches dans l'espace : respectivement vingt-sept pièces au mètre carré contre quatre cent trente...

Tableau 2 : Décompte des pièces en silex découvertes dans les sondages de 2011, classées par principales catégories du débitage et de l'outillage.

Table 2 : Detail of the lithic artifacts discovered in the 2011 trenches, ordered within the main debitage and tool categories.

\begin{tabular}{|l|l|l|l|l|l|l|l|l|l|l|}
\hline Support & Fraction & A & B & C & D & E & F & H & J & Total \\
\hline Galet & Entier & & & & & & 1 & & & 1 \\
\hline & Fragment & & & & 2 & 1 & & & & 3 \\
\hline Éclat cortical & Entier & 2 & & & 30 & 10 & & 2 & & 44 \\
\hline & Proximal & 3 & & & 16 & 5 & & & & 24 \\
\hline & Mésial & 1 & & 1 & 22 & 7 & & & & 31 \\
\hline & Distal & 3 & & 1 & 22 & 4 & & & & 30 \\
\hline Éclat semi-cortical & Entier & 7 & & 1 & 36 & 6 & & & 1 & 51 \\
\hline & Proximal & 3 & & & 17 & 2 & & & & 22 \\
\hline & Mésial & & & & 10 & & & 2 & & 12 \\
\hline & Distal & 3 & & 4 & 9 & & & & & 16 \\
\hline & Entier & 35 & 5 & 5 & 131 & 31 & 3 & & & 210 \\
\hline & Proximal & 10 & 5 & 5 & 105 & 24 & 1 & & & 150 \\
\hline
\end{tabular}




\begin{tabular}{|c|c|c|c|c|c|c|c|c|c|c|}
\hline & Mésial & 3 & 4 & 2 & 76 & 22 & & & & 107 \\
\hline & Distal & 5 & 1 & & 43 & 1 & & & & 50 \\
\hline \multirow[t]{2}{*}{ Éclat cortical perc./encl. } & Entier & & & & 2 & & & & & 2 \\
\hline & Proximal & 1 & & & & & & & & 1 \\
\hline \multirow[t]{3}{*}{ Éclat perc./enclume } & Entier & & & & 3 & . & & & & 3 \\
\hline & Proximal & & & & 1 & & & & & 1 \\
\hline & Mésial & & & & 7 & & & & & 7 \\
\hline Lame corticale & Proximal & . & & & 1 & & & & & 1 \\
\hline \multirow[t]{4}{*}{ Lame } & Entier & & & & & 2 & & & & 2 \\
\hline & Proximal & 1 & & & 5 & & & & & 6 \\
\hline & Mésial & & & & 4 & 1 & & & & 5 \\
\hline & Distal & & & & 2 & 1 & & & & 3 \\
\hline \multirow[t]{4}{*}{ Lamelle } & Entier & 1 & & & 1 & 3 & & & & 5 \\
\hline & Proximal & 1 & & & 25 & 5 & & & & 31 \\
\hline & Mésial & 1 & & 3 & 21 & 2 & & & & 27 \\
\hline & Distal & & & & 4 & & & & & 4 \\
\hline \multirow[t]{2}{*}{ Lame à néo-crête } & Proximal & 1 & & & & & & & & 1 \\
\hline & Mésial & & & & 1 & & & & & 1 \\
\hline \multirow[t]{2}{*}{ Lamelle à néo-crête } & Entier & & & & 2 & 1 & & & & 3 \\
\hline & Mésial & & & & & 1 & & & & 1 \\
\hline \multirow[t]{2}{*}{ Éclat à néo-crête } & Entier & & & & & 1 & & & & 1 \\
\hline & Distal & & & & & 1 & & & & 1 \\
\hline Tablette partielle & Entier & & & & 3 & 1 & & & & 4 \\
\hline Nucleus & Entier & 3 & 1 & & 7 & 3 & 3 & & & 17 \\
\hline Esquille & & 16 & 2 & 9 & 2011 & 544 & & & & 2582 \\
\hline Casson & & 32 & 4 & 5 & 347 & 80 & 1 & 6 & & 475 \\
\hline Total des pièces brutes & & 132 & 22 & 36 & 2966 & 759 & 9 & 10 & 1 & 3935 \\
\hline
\end{tabular}




\begin{tabular}{|l|l|l|l|l|l|l|l|l|l|l|}
\hline Total des outils & & $\mathbf{4}$ & $\mathbf{3}$ & $\mathbf{0}$ & $\mathbf{4 5}$ & $\mathbf{1 3}$ & $\mathbf{0}$ & $\mathbf{0}$ & $\mathbf{0}$ & $\mathbf{6 5}$ \\
\hline Total général & & $\mathbf{1 3 6}$ & $\mathbf{2 5}$ & $\mathbf{3 6}$ & $\mathbf{3 0 1 1}$ & $\mathbf{7 7 2}$ & $\mathbf{9}$ & $\mathbf{1 0}$ & $\mathbf{1}$ & $\mathbf{4 0 0 0}$ \\
\hline Pièces brûlées (hors esquilles) & $N$ & 50 & 11 & 17 & 553 & 124 & 2 & 8 & 0 & 765 \\
\hline & $\%$ & 36,8 & 44,0 & 47,2 & 18,4 & 16,1 & 22,2 & 80,0 & 0,0 & 19,1 \\
\hline
\end{tabular}

Les deux dernières lignes donnent le nombre et la proportion de pièces brûlées, hors esquilles (mais avec les pièces brutes et les outils).

The last two lines indicate the number and the proportion of burnt objects, excepting flakes (but with brut cores and tools).

Le taux général de pièces altérées par le feu après leur débitage est de $19 \%$, ce qui est relativement bas pour un site de cette période en Bretagne. Il est nettement plus élevé dans les sondages $\mathrm{A}, \mathrm{B}, \mathrm{C}, \mathrm{F}$ et $\mathrm{H}$ que dans les deux sondages $\mathrm{D}$ et $\mathrm{E}$, car ce sont essentiellement des cassons brûlés d'assez grandes dimensions qui témoignent de ces atteintes thermiques (nous avons exclu les esquilles de ce décompte des éléments affectés par le feu). Toutes les pièces lithiques ont été observées à la loupe binoculaire, avec un grossissement de dix à quarante. Bien que les patines soient peu prononcées, on constate alors des états de surface assez lamentables: voile blanchâtre sur les surfaces, bords rognés, nervures abrasées, pointes cassées, surfaces brillantes disposées de manière aléatoire, nombreux impacts post-dépositionnels. Aucune analyse tracéologique de grande envergure n'est donc envisageable. On signalera toutefois que, dans le cadre d'un travail plus général sur ces outils, C. Guéret avait observé en 2010 une lame à coches aménagées (dites lame Montbani) découverte en surface et qu'il y avait décelé un travail des plantes, l'intérieur de la coche étant la zone active. Par ailleurs, les stigmates d'impact sont bel et bien présents sur les armatures avec, sans surprise, un fonctionnement en flèches tranchantes. Nous avons accru le corpus découvert en fouille de celui récolté en surface, afin de valider les observations dont il sera fait état plus loin.

\section{Méthodes et techniques du débitage}

\section{Matières premières}

Les galets glanés sur les plages sont l'unique source de silex utilisé sur ce site. Quatre mille pièces ont été recueillies dans huit sondages $\left(29 \mathrm{~m}^{2}\right)$. À l'heure actuelle, cette ressource est des plus rares à Belle-Île et on en trouve essentiellement sur la plage des Grands Sables, au nord-est de l'île, face au continent. Il n'y a pas de quoi alimenter la production d'un site comme celui de Bordelann, sans parler de tous les autres sites contemporains déjà connus (et des autres à découvrir...). On doit alors envisager trois hypothèses :

- les plages à galets de silex étaient plus nombreuses car plus proches des gisements crétacés sous-marins, mais la transgression marine (environ 10 ou 15 mètres) les a submergées ;

- les galets étaient importés depuis les plages du continent ;

- la ressource a été épuisée après un usage intensif au Mésolithique et au Néolithique, alors qu'après 7000 avant notre ère, le rythme de la transgression s'était singulièrement ralentie et donc que l'alimentation des cordons de galets connaissait une substantielle diminution. 
24

tes ces hypothèses pourront être testées à l'avenir par des plongées sousmarines en avant des falaises actuelles (pour la première) et des analyses micropaléontologiques des silex peut-être (pour la seconde). Mais il n'est pas certain que l'on puisse trouver une réponse univoque. La conséquence évidente de cette pénurie de matières siliceuses taillables est l'extrême petitesse des produits obtenus et des nucléus : les galets mesurent en général moins de cinquante millimètres, les éclats font moins de trente millimètres de long pour autant de large avec, dans la grande majorité des cas, des plages corticales en partie distale qui signalent les dimensions modestes des tables de débitage. Plusieurs caractères originaux de cette série en regard des productions continentales peuvent découler de ces petites dimensions des galets, comme la quasi-absence des séquences laminaires et lamellaires au profit d'une production d'éclats fins et courts, mais aussi l'absence de stigmates de la percussion indirecte.

La question de l'usage du quartz a été posée d'emblée lors de l'intervention, puisqu'en surface, ces restes abondent et que certains portent traces d'une fracture conchoïdale. De ce fait, tous les fragments ont été recueillis lors les sondages. Cette pétition de principe s'est bien sûr heurtée à la réalité géologique, puisque le micaschiste plissé du substrat est marbré de veines de quartz désagrégées. Après avoir écarté les éléments portant des inclusions de micaschiste, nous avons recueilli 319 éléments de quartz, mais nous sommes bien en peine de discuter de leur fragmentation par le travail volontaire des hommes et des femmes de la préhistoire. Certaines pièces, rares quand même, procèdent à l'évidence d'une cassure conchoïdale, mais peut-être s'agit-il d'impact de charrue? Cela nous interdit de les décompter avec le silex et d'en comparer les proportions, comme nous le faisons d'ordinaire pour traiter des roches de substitution à l'intérieur de la Bretagne. En contexte de pénurie extrême du silex et en l'absence d'autres roches taillables sur cette île, l'usage du quartz est très probable, mais nous éprouvons des difficultés à en rendre compte. Il peut s'agir de galets de quartz, par ailleurs utilisés comme percuteurs, mais aussi de certains filons suffisamment larges et de belle qualité qui auraient pu être exploités régulièrement par les habitants de l'île. Il y a là, assurément, une belle mais austère problématique de recherche, propre à ce territoire insulaire, mais nous hésitons à nous y engager.

Les galets de grès-quartzite de couleur brune à la texture homogène et de grande densité représentent une autre ressource, dont le débitage ne fait cette fois pas de doute. Neuf fragments d'éclats en témoignent dans les sondages et plus de deux kilos d'objets dans la collection de surface. Dans celle-ci, un chopper unifacial sur éclat, trouvé en surface (fig. 8), nous désigne un des objectifs de cette production, qui comprend aussi des éclats denticulés massifs. Aucune méthode complexe n'a pour l'instant été détectée dans l'agencement des enlèvements, sinon un débitage de gros éclats au gré des convexités, qui reste à mieux décrire à partir de la collection de surface. 
Figure 8 : Chopper sur éclat en quartzite (galet marin), trouvé en surface. Figure 8 : Denticulate flake realised on a quartzite pebble.
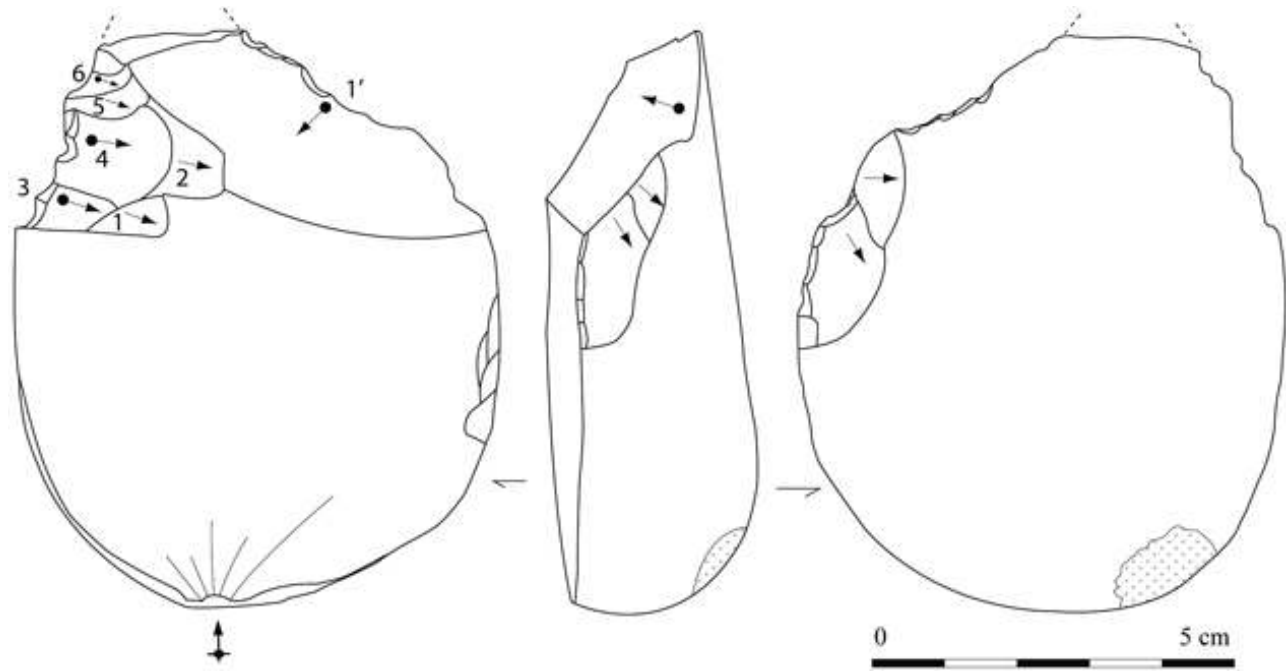

DAO G. Marchand.

D'autres matériaux ont également été utilisés par les hommes et les femmes, non pas en substitution du silex mais en complément, c'est-à-dire pour la réalisation d'autres activités. Il s'agit soit de percuteurs en quartz, soit d'un galet de cornéenne aux bords striés par des activités, soit d'un percuteur/enclume en granite (sondage D, carré 1 , US 2 ; fig. 9, $\mathrm{n}^{\circ} 1$ ). La datation de ce dernier objet est hélas impossible, mais il faut noter l'absence de granite dans le substrat de l'île, ce qui implique une importation depuis des plages de Houat et Hoëdic ou bien de Quiberon. 


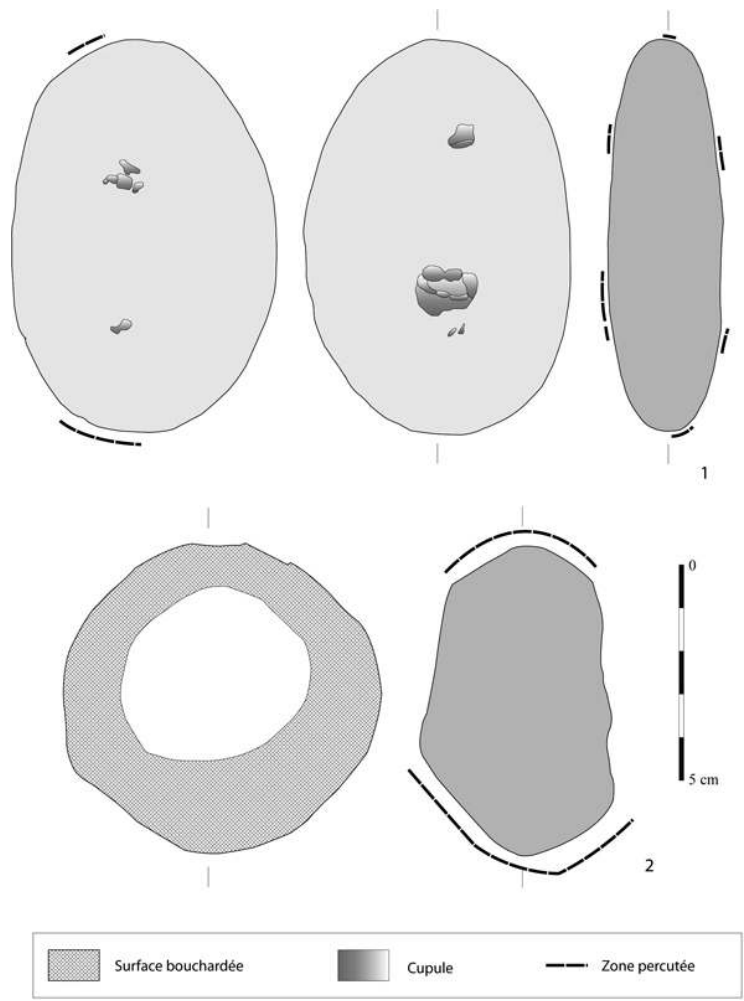

1 : percuteur et enclume sur galet de granite (D1, US 2) ; 2 : boucharde en quartz filonien (sondage D, hors US).

1 : hammer ; 2 : bush hammer.

DAO G. Marchand.

\section{Les objectifs de la production sur galets de silex}

La production sur place de l'outillage en silex ne fait guère de doute, au vu de la grande densité de pièces lithiques. Parmi les esquilles, on distinguera les cassons d'une dimension inférieure à dix millimètres, les esquilles de retouche à profil en «aile d'oiseau » et les esquilles d'abrasion de la corniche. On notera ensuite que toutes les catégories attendues de produits sont présentes: entames, éclats corticaux initiaux, éclats corticaux et semi-corticaux émanant du cours du débitage et éclats de plein débitage. Cependant, en un tel contexte sédimentaire, avec des chaînes opératoires relativement simples et une telle masse de pièces, il serait illusoire de chercher à traiter la question pourtant fondamentale des importations et exportations de supports.

La production d'éclats minces est au centre des objectifs du débitage si l'on en juge par la nature des supports. Ils seront distribués, pour les plus menus, sans cortex comme support d'armature, dont on note ici la grande diversité. Les derniers enlèvements des nucléus correspondent d'ailleurs à ces supports, de la même manière que dans les assemblages du continent, où la largeur des dernières lamelles sur les tables recouvre celle des plus petits supports de bitroncatures. Certains éclats non corticaux peuvent être utilisés pour des perçoirs ou des denticulés, mais le nombre de ces objets est infime dans les sondages et faible en surface. De ce fait, aucune démarche standard dans l'usage des supports corticaux, semi-corticaux et non corticaux épais n'est perceptible. 
Cette incertitude découle directement de la structure même du débitage, qui s'affranchit des règles en usage dans le second Mésolithique continental, là où la matière abonde davantage. Il n'a pas été possible de tenir compte des traces d'usage sur les tranchants, qui étaient trop abîmés par leur séjour dans des niveaux assez chahutés.

Si on observe les supports des armatures, on notera près de $12 \%$ de lames et $38 \%$ de lamelles (tableau 5). Par ailleurs, il existe dans le mobilier de surface quatre couteaux à dos entiers et un fragment (fig. 19), dont aucun ne fut réalisé sur lames mais plutôt sur des éclats larges et allongés, sans cortex, issus de séquences unipolaires courtes (plusieurs sens de débitage apparaissent alors sur les faces supérieures). Quelle est donc l'origine de ces supports allongés? Lames et lamelles comptent pour $10 \%$ des supports bruts (corticaux, semi-corticaux et a-corticaux), ce qui est faible. La proportion est similaire si on considère seulement les pièces a-corticales entières et proximales : lames et lamelles comptent alors pour $10,9 \%$. Qui plus est, ces produits ne procèdent pas pour la plupart d'opérations récurrentes.

31 Pour les armatures, même si on peut concevoir des erreurs de détermination dans notre nomenclature des supports raccourcis par les troncatures, il n'en reste pas moins qu'un certain nombre sont des lamelles régulières à trois pans. On va certes en trouver quelques-unes dans le débitage, avec d'ailleurs un mode de préparation des corniches plus soigné. Mais il n'y a pas de nucléus correspondant, ni d'ailleurs d'éclats d'entretien de telles surfaces de débitage. Nous ne pouvons raisonnablement pas soutenir que ces produits sont importés, mais la possibilité en est ouverte.

\section{Une méthode unipolaire frontale}

Parmi les dix-sept nucléus issus des sondages, treize recueillis dans la cuvette ont fait l'objet d'une analyse assez poussée, complétée qualitativement par un examen des 271 nucléus récoltés en surface (décompte de L. Ouradi). Les petites dimensions des galets ont à l'évidence contraint les opérations : la longueur moyenne des nucléus est de trente millimètres (entre 20 et $38 \mathrm{~mm}$ ) et celle des tables de seulement vingt-trois millimètres (entre 11 et $33 \mathrm{~mm}$ ). Les derniers enlèvements mesurent entre dix et vingtdeux millimètres de long (moyenne $16 \mathrm{~mm}$ pour $14 \mathrm{~mm}$ de large). Avec d'aussi faibles dimensions, la gestion des convexités est peu contraignante, ce qui explique le nombre très faible de pièces à néo-crête ou de tablettes, toujours partielles d'ailleurs (fig. 10). N'oublions pas cependant l'existence de quelques lamelles allongées: il existe probablement une production récurrente de produits de meilleure tenue, mais nous n'avons pas encore pu en distinguer les traces de production dans le matériel de surface (ni a fortiori dans ces sondages). 
Figure 10 : Nucléus trouvés dans les sondages. Figure 10 : Cores found during the excavation.

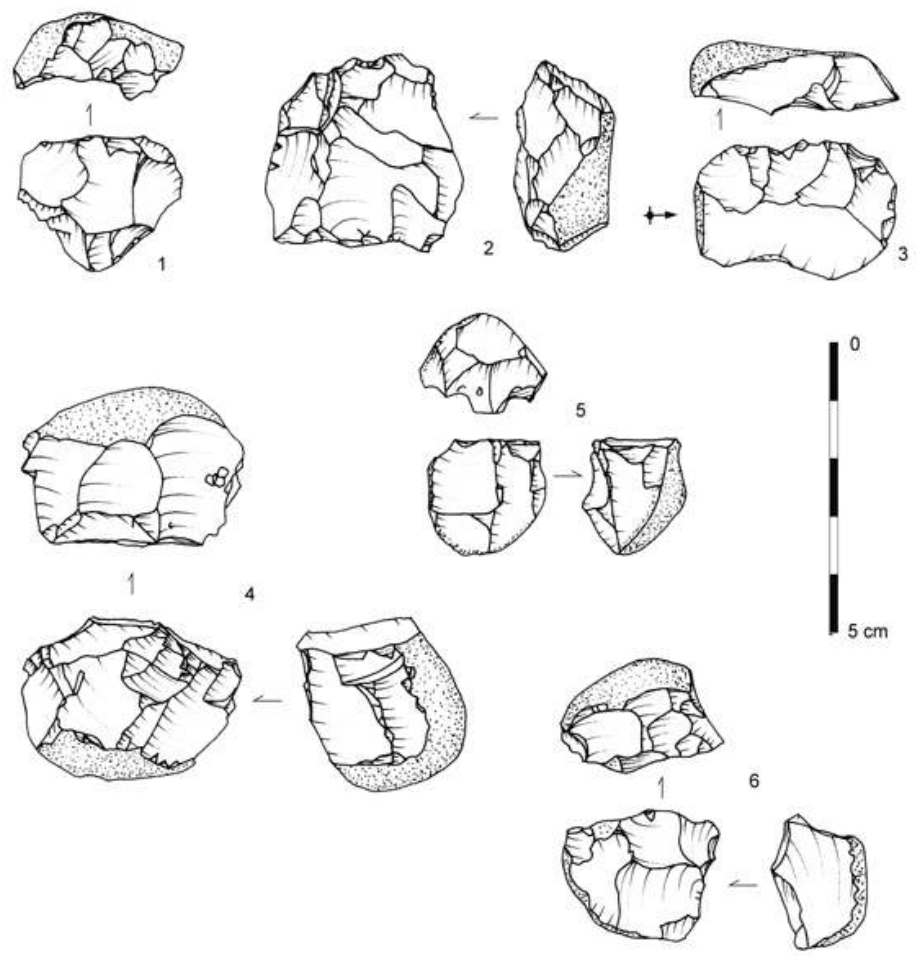

1 : Nucléus unipolaire en phase terminale (A4, US 1) ; 2 : Nucléus bipolaire sur une même table, avec des enlèvements réalisés à partir du dos cortical (E2, US 2) ; 3 : Nucléus unipolaire sur éclat (D6, US 1) ; 4 : Nucléus portant deux séquences successives unipolaires, qui se recoupent de manière orthogonale (D6, US 1) ; 5 : Nucléus unipolaire (D9, US 1); 6 : Nucléus bipolaire angulaire sur une même table, qui succède à une autre table unipolaire (D3, US 1).

\section{Dessins G. Marchand.}

Le nucléus «standard » est un galet décalotté par un coup transversal à une extrémité, plus rarement un gros éclat ayant servi à fragmenter le galet. On signalera dans ce cas une table établie sur la face inférieure avec un plan de frappe qui correspond à une ancienne table (D6, US 1 - fig. 10, $\mathrm{n}^{\circ}$ ). Le débitage se fait par une succession de séquences unipolaires comprenant chacune quelques enlèvements ( 3 ou 4). La table reste restreinte à une partie du volume, avec des extensions latérales fort minimes. La succession de ces tables suit la configuration volumétrique des blocs travaillés. Si un nucléus montre un travail sur une même table à partir de deux plans de frappe avec même une correction du cintre à partir du dos (E2, US 2 - fig. 10, $n^{\circ} 2$ ), les séquences successives se font plutôt dans plusieurs plans sécants. On observe fréquemment la transformation d'un plan de frappe en table, l'ancienne table, logiquement orthogonale, devenant le plan de frappe (D3, US $1-\mathrm{n}^{\circ} 6$ et D6 ; US $1-\mathrm{n}^{\circ} 4$; A5, US 1).

Les plans de frappe sont rarement lisses, témoignant d'une histoire antérieure qui, pour être assez courte et techniquement simple, n'en existe pas moins. Il n'y a pas de micro-facettage. L'abrasion des corniches est sommaire et la seule technique détectée est la percussion directe dure. Malgré les petites dimensions des galets de silex, la percussion bipolaire sur enclume n'est guère mise en œuvre. L'idée tenace qu'il s'agit de la seule manière d'aborder de petits galets de silex trouve encore une fois un démenti mais, en ce domaine, les idées préconçues ont toujours la vie dure... À 
Bordelann, certains galets ont été ouverts sur enclume et, d'ailleurs, nous avons trouvé un instrument de cette nature dans le sondage $\mathrm{D}$, avec de faibles traces d'utilisation. Mais il s'agit de proportions dérisoires, sans aucun rapport avec les pratiques néolithiques (tableau 2). Cette observation vient d'ailleurs nous confirmer que la composante néolithique ou de l'âge du Bronze reste ultra-minoritaire, car à partir du IV ${ }^{\mathrm{e}}$ millénaire, cette méthode est prépondérante dans l'Ouest de la France (Guyodo et Marchand, 2005). Ces occupations ultérieures existent-elles même? Seuls les huit tessons dans les sondages, une molette en surface et éventuellement les bitroncatures symétriques allongées en ouvrent la possibilité, ce qui nous autorise pour le moins à nous interroger sur la nature réelle de cette "intrusion" au sein d'un corpus très largement mésolithique.

Les produits obtenus sont des éclats courts et minces, avec très fréquemment du cortex en partie distale. Il existe bien évidemment de nombreux éclats débordants avec un pan cortical ou un pan très abrupt naturellement, mais ils ne semblent pas porter d'aménagement ou d'esquillement particulier (une analyse tracéologique serait dans ce cas intéressante, mais plutôt sur un corpus mieux préservé). De manière plus générale, le très faible nombre d'outils aménagés hors des armatures nous empêche d'approfondir les notions d'économie du débitage, qui aurait vu la production d'un type de support particulier en plus des éclats minces destinés aux armatures.

\section{L'outillage aménagé : des bitroncatures plus que tout autre chose...}

Évacuons rapidement la question des outils aménagés : on note deux éclats à coche, un grattoir fendu en deux longitudinalement mais au front très peu développé, un éclat à bord abattu et quatre troncatures sur éclat (tableau 3). Un perçoir sur éclat, réalisé par une troncature concave est également à noter; il est long de quinze millimètres avec une silhouette trapue; sa pointe est émoussée. Les autres outils sont des éclats à tranchant usé ou esquillé dont le chiffrage, dans ce contexte, est sans intérêt réel. Ce n'est pas le cas évidemment des deux pièces esquillées, qui ne peuvent procéder d'accidents ou de piétinements.

Tableau 3 : Décompte des outils en silex découverts dans les sondages de 2011. Table 3 : Detail of flint tools discovered in the 2011 trenches.

\begin{tabular}{|l|l|l|l|l|l|l|l|l|l|l|}
\hline Type & Fraction & A & B & C & D & E & F & H & J & Total \\
\hline Bitroncature symétrique & Entier & 1 & 1 & & 7 & 4 & & & 13 \\
\hline & Fragment & & & 8 & 3 & & & & 11 \\
\hline Triangle scalène & Entier & & & & & 1 & & & & 1 \\
\hline Monotroncature symétrique & Entier & & & & 3 & & & & 3 \\
\hline Armature diverse & Fragment & & & 6 & 2 & & & 8 \\
\hline Coche & Entier & & & & 2 & & & & 2 \\
\hline Grattoir & Fragment & & & 1 & & & & 1 \\
\hline
\end{tabular}




\begin{tabular}{|c|c|c|c|c|c|c|c|c|c|c|}
\hline Perçoir & Entier & & & & 1 & & & & & 1 \\
\hline Bord abattu & Entier & & 1 & & & & & & & 1 \\
\hline Troncature oblique rectiligne & Entier & 1 & & & 2 & & & & & 3 \\
\hline Troncature transverse rectiligne & Entier & & & & 1 & & & & & 1 \\
\hline & Fragment & & & & 1 & & & & & 1 \\
\hline Retouches d'aménagement diverses & Fragment & & & & 6 & & & & & 6 \\
\hline Éclat/lame à retouches continues & Fragment & 1 & & & & & & & & 1 \\
\hline Éclat/lame à retouches partielles & Entier & & & & 3 & & & & & 3 \\
\hline Pièce esquillée & Entier & 1 & & & & 1 & & & & 2 \\
\hline Éclat/lame à coche d'usage & Entier & & & & & & & & & 0 \\
\hline Éclat/lame à esquilles & Entier & & & & & & & & & 0 \\
\hline Éclat/lame à fil ébréché continu & Entier & & & & 4 & 1 & & & & 5 \\
\hline Éclat/lame à fil ébréché discontinu & Entier & & 1 & & & 1 & & & & 2 \\
\hline Total & & 4 & 3 & 0 & 45 & 13 & 0 & 0 & 0 & 65 \\
\hline
\end{tabular}

Il convient de s'attarder davantage sur les armatures, représentées par dix-sept pièces entières et dix-neuf fragments. Pour cette étude, nous avons également travaillé sur les quatre-vingt-seize armatures recueillies en surface (tableau 4). Il s'agit à $95 \%$ de bitroncatures symétriques dites aussi trapèzes symétriques, réalisées par deux troncatures convergentes mais non sécantes (bitroncatures symétriques trapézoïdales), plus rarement par une troncature opposée à un bord rebroussé ou naturel (monotroncature) et encore plus rarement par deux troncatures convergentes sécantes (bitroncatures symétriques triangulaires) (fig. 11 et 12). Les supports sont plutôt des éclats que des lamelles (tableau 5).

Tableau 4 : Décompte des armatures en silex découvertes dans les sondages de 2011 et en surface.

Table 4 : Detail of the flint arrowheads discovered in the 2011 trenches and on the surface.

\begin{tabular}{|l|l|l|l|}
\hline Type & Sondages 2011 & Surface & Total général \\
\hline Bitroncature symétrique & 21 & 56 & 77 \\
\hline Bitroncature symétrique (allongée) & 2 & 10 & 12 \\
\hline Monotroncature symétrique & 3 & 4 & 7 \\
\hline Monotroncature triangulaire & & 2 & 2 \\
\hline
\end{tabular}




\begin{tabular}{|l|l|l|l|}
\hline Bitroncature asymétrique & & 2 & 2 \\
\hline Segment & & 2 & 2 \\
\hline Triangle scalène & 1 & & 1 \\
\hline Troncature (frag.) & 3 & 19 & 22 \\
\hline
\end{tabular}

Le nombre d'armatures des sondages ne prend pas en compte tous les fragments recueillis difficiles à identifier, le total réel atteignant trente-six éléments.

The number of arrowheads from the trenches excludes the unidentified fragments corresponding to 36 elements.

Tableau 5 : Support des armatures.

Table 5 : arrowhead supports.

\begin{tabular}{|l|l|l|l|l|}
\hline Types & Éclat & Inconnu & Lame & Lamelle \\
\hline Bitroncature asymétrique & $0,0 \%$ & $0,0 \%$ & $0,0 \%$ & $100,0 \%$ \\
\hline Bitroncature symétrique & $40,3 \%$ & $1,3 \%$ & $11,7 \%$ & $46,8 \%$ \\
\hline Bitroncature symétrique (allongée) & $91,7 \%$ & $0,0 \%$ & $8,3 \%$ & $0,0 \%$ \\
\hline Monotroncature symétrique & $71,4 \%$ & $0,0 \%$ & $14,3 \%$ & $14,3 \%$ \\
\hline Troncature (frag.) & $22,7 \%$ & $31,8 \%$ & $13,6 \%$ & $31,8 \%$ \\
\hline Total général & $\mathbf{4 3 , 3} \%$ & $\mathbf{6 , 7} \%$ & $\mathbf{1 1 , 7} \%$ & $\mathbf{3 8 , 3} \%$ \\
\hline
\end{tabular}

Surface et sondage $; \mathrm{N}=120$

Surface and trench; $N=120$ 
Figure 11 : Armatures des sondages 2011 à Bordelann (Sauzon). Figure 11 : Arrowheads found in the excavations.
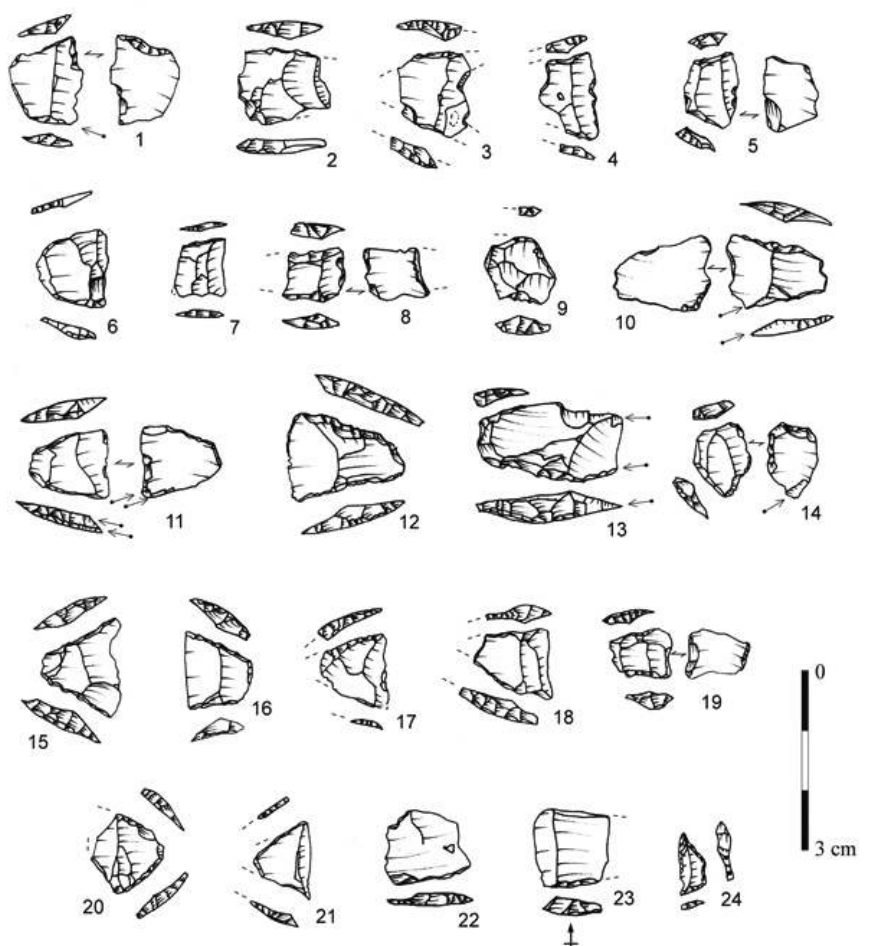

1 à 23 : bitroncatures symétriques courtes ou allongées (nos 12 et 13) ; 24 : triangle scalène étroit. Dessins G. Marchand.

Figure 12 - Répartition des différents types d'armature à Bordelann.

Figure 12 : Different types of arrowheads (excavations and surface finds).

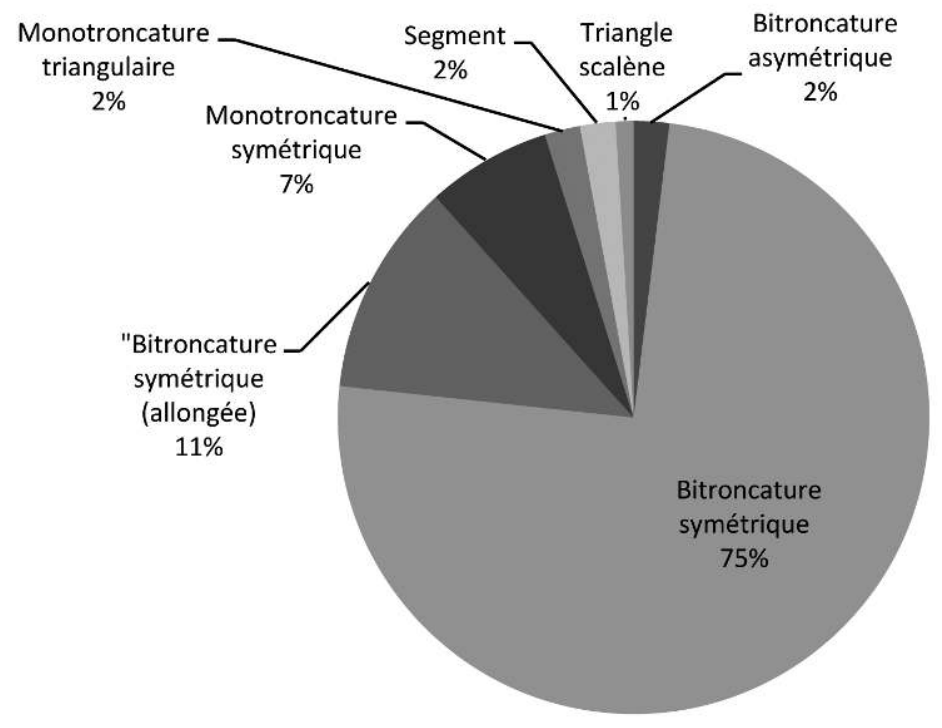

Surface et sondages : $N=103$. 
En ce qui concerne la population de bitroncatures symétriques trapézoïdales, nous avons été amenés sur ce site à distinguer deux sous-types par leurs dimensions et leurs proportions (fig. 13 à 17) :

- Les bitroncatures symétriques courtes ont une grande base (= longueur ou tranchant) un peu plus longue que leur largeur (tableau 6 et 7). On notera que les monotroncatures entrent toutes dans ces dimensions et qu'elles peuvent leur être assimilées d'un point de vue fonctionnel. Ces dernières sont des pièces symétriques sur éclat mince, dont l'un des bords est une troncature directe et l'autre un rebroussé. Toutes ces armatures ont été réalisées sur différents types de supports minces, pourvu qu'ils fussent sans cortex, où les lames et lamelles comptent quand même pour $60 \%$ alors que ces supports sont anecdotiques dans le débitage. Les troncatures sont en général directes et abruptes. Quelques associations entre une troncature directe et une troncature inverse sont notées $(13,5 \%)$. Les troncatures alternantes sont encore plus rares. Pour $78 \%$ des exemplaires analysés, la délinéation des troncatures est rectiligne. Dans le cas contraire, la concavité est très peu prononcée ; elle se traduit par une légère asymétrie de la pièce lorsque les deux troncatures n'ont pas la même délinéation (par exemple, fig. $11, \mathrm{n}^{\circ} 3$ ou 18). Ces armatures sont très abîmées par leur séjour dans la terre; les bases portent une sorte de grignotage qui altère évidemment les éventuels stigmates de nature fonctionnelle. Nous avons eu, à plusieurs reprises, la preuve de fausses traces burinantes, grâce à une altération de la patine des pièces, mais bon nombre procèdent à l'évidence de réels impacts qui engendrent des enlèvements de plusieurs millimètres de long. Dans le sondage, $12,5 \%$ de ces pièces portent un impact burinant plan, et 37,5\% un impact burinant affectant une troncature. Ces taux sont respectivement de 22 et $17 \%$ en surface. Une ou deux des "pointes» sont fréquemment cassées ( $38 \%$ en sondage, $52 \%$ en surface). Un quart des petites bases ont une cassure nette et $4 \%$ présentent une cassure en flexion. Malgré l'altération générale des surfaces de ces pièces, ces stigmates nous semblent pouvoir être rapportés à un usage exclusif en flèches tranchantes.

Tableau 6 : Comparaison entre les proportions des bitroncatures symétriques courtes et allongées Table 6 : Comparison of the proportion of short and long symmetrical bitroncatures

\begin{tabular}{|l|l|l|l|l|l|l|l|}
\hline $\begin{array}{l}\text { Bitroncature } \\
\text { symétrique } \\
\text { (courte) }\end{array}$ & $\begin{array}{l}\text { Rapport } \\
\text { Longueur } \\
\text { Largeur }\end{array}$ & $\begin{array}{l}\text { Rapport } \\
\text { Largeur } \\
\text { Petite } \\
\text { Base }\end{array}$ & $\begin{array}{l}\text { Rapport } \\
\text { Longueur } \\
\text { Petite base }\end{array}$ & $\begin{array}{l}\text { Bitroncature } \\
\text { symétrique } \\
\text { (allongée) }\end{array}$ & $\begin{array}{l}\text { Rapport } \\
\text { Longueur } \\
\text { Largeur }\end{array}$ & $\begin{array}{l}\text { Rapport } \\
\text { Largeur / } \\
\text { Petite } \\
\text { Base }\end{array}$ & $\begin{array}{l}\text { Rapport } \\
\text { Longueur } \\
\text { Petite base }\end{array}$ \\
\hline Moyenne & 1,11 & 1,60 & 1,78 & Moyenne & 0,66 & 3,38 & 2,16 \\
\hline Écart-type & 0,20 & 0,74 & 0,85 & Écart-type & 0,10 & 1,38 & 0,75 \\
\hline Maximum & 1,72 & 4,65 & 5,03 & Maximum & 0,79 & 6,89 & 3,79 \\
\hline Minimum & 0,72 & 0,86 & 1,03 & Minimum & 0,49 & 2,26 & 1,30 \\
\hline
\end{tabular}


Tableau 7 : Principales dimensions des armatures. Table 7 : Main dimensions of the arrowheads.

\begin{tabular}{|l|l|l|l|l|}
\hline \multicolumn{5}{|l|}{ Bitroncature symétrique (courte) } \\
\hline & Longueur & Largeur & Épaisseur & Petite base \\
\hline Moyenne & 13,08 & 12,01 & 2,66 & 8,00 \\
\hline Écart-type & 2,17 & 1,99 & 0,65 & 2,03 \\
\hline Maximum & 20,10 & 16,80 & 4,10 & 12,21 \\
\hline Minimum & 8,60 & 7,82 & 1,30 & 2,47 \\
\hline Bitroncature symétrique (allongée) \\
\hline Moyenne & 11,49 & 17,72 & 3,36 & 5,74 \\
\hline Écart-type & 1,38 & 2,27 & 0,71 & 1,48 \\
\hline Maximum & 13,59 & 23,60 & 4,90 & 7,35 \\
\hline Minimum & 8,53 & 16,15 & 2,25 & 2,85 \\
\hline Bitroncature symétriques (toutes) & 7,58 \\
\hline Moyenne & 12,80 & 12,90 & 2,75 & 2,12 \\
\hline Écart-type & 2,14 & 2,91 & 0,69 & 12,21 \\
\hline Maximum & 20,10 & 23,60 & 4,90 & 2,47 \\
\hline Minimum & 8,53 & 7,82 & 1,30 & \\
\hline
\end{tabular}

La largeur correspond à la largeur du support, la longueur est égale à la grande base.

The width corresponds to the support width and the length corresponds to the large base. 
Figure 13 : Longueur, largeur et longueur de la petite base des bitroncatures symétriques courtes et allongées (surface et sondages).

Figure 13 : Length, width and length of the small base of the symmetric bitroncations (excavations and surface finds).

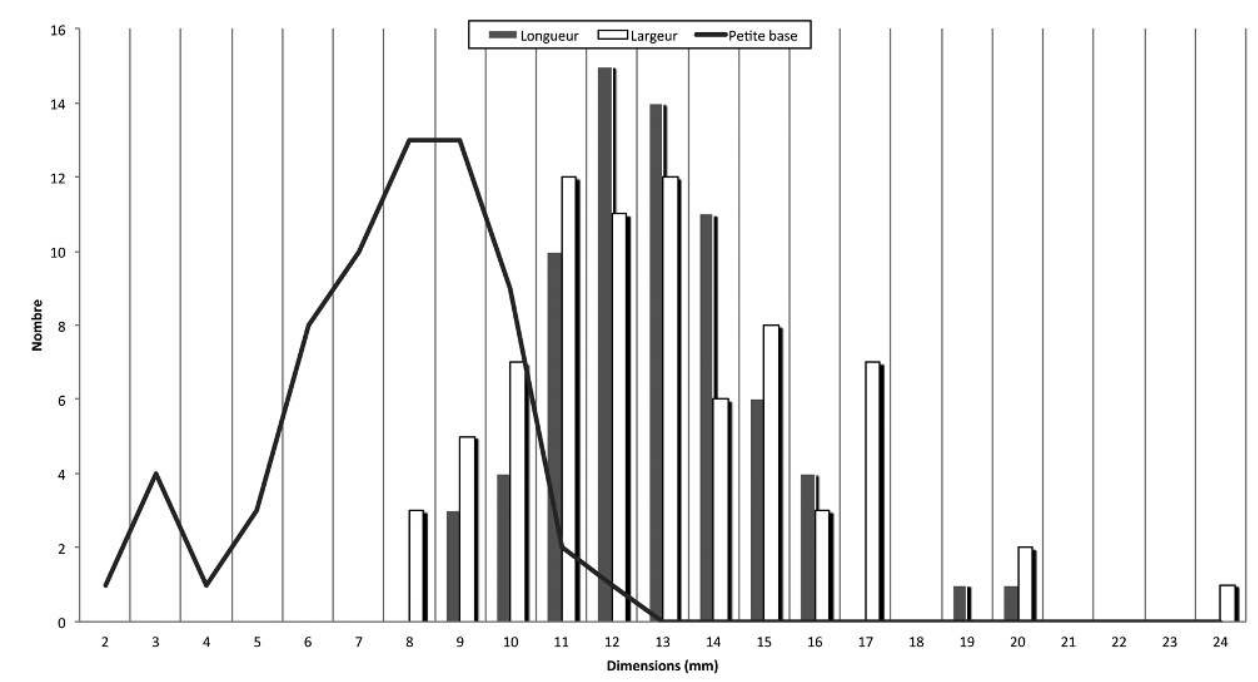

- Les bitroncatures symétriques allongées (deux dans les sondages, dix en surface) ont une grande base nettement plus courte que la largeur, le rapport longueur/largeur étant en moyenne de 0,66 contre 1,11 pour les précédentes. En outre, leur largeur est supérieure à seize millimètres. Leur petite base est significativement plus courte que celle des bitroncatures symétriques courtes (fig. 17). Les coefficients de corrélation entre longueur et largeur montrent une absence de standardisation pour ces bitroncatures allongées, au contraire des courtes (0,16 contre 0,44). Tous les autres coefficients montrent une absence de liens entre les différentes dimensions. Les supports sont des éclats plus épais que les supports des bitroncatures courtes, ce qui explique les deux "pics » du diagramme des épaisseurs (fig. 14). Il y a davantage de retouches alternantes, parfois croisées sur enclume, ou d'association entre une troncature directe d'un côté et une troncature inverse de l'autre. On ne distingue pas en revanche de styles d'exécution différents. Que ce soit en surface ou dans le sondage, ces armatures ne sont quasiment pas altérées par le feu, contrairement aux autres. 
Figure 14 : Épaisseur des bitroncatures symétriques courtes et allongées (surface et sondages). Figure 14 : Thickness of the symmetric bitroncations (excavations and surface finds).

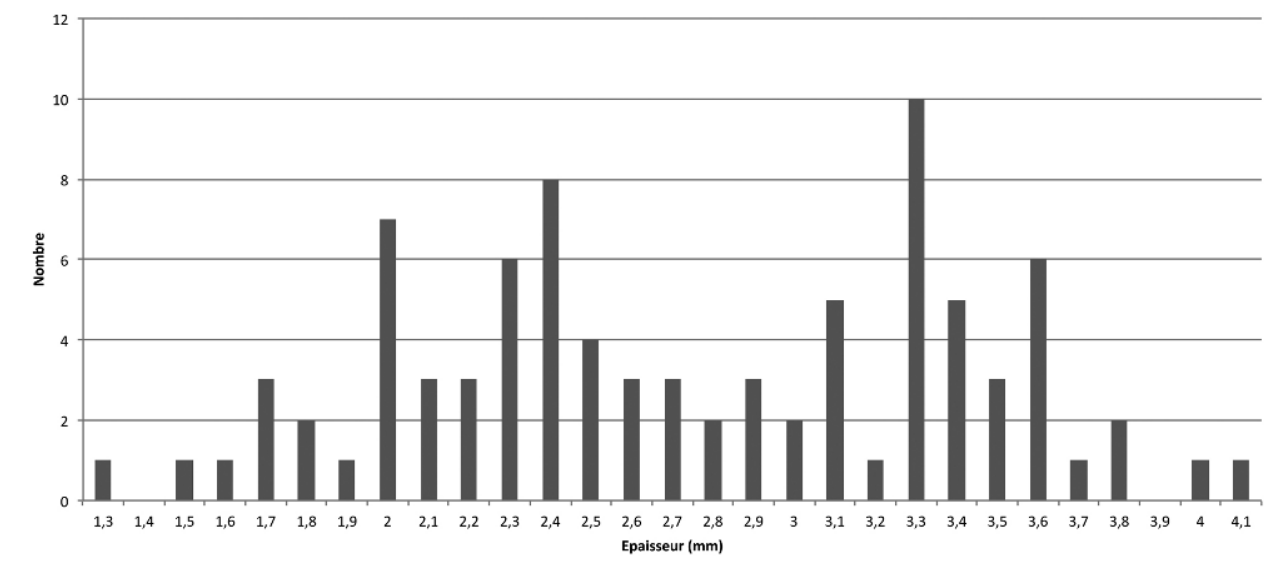

Figure 15 : Longueur et largeur des bitroncatures symétriques et des monotroncatures (surface et sondages).

Figure 15 : Length and width of the symmetric bitroncations and the monotruncations (excavations and surface finds).

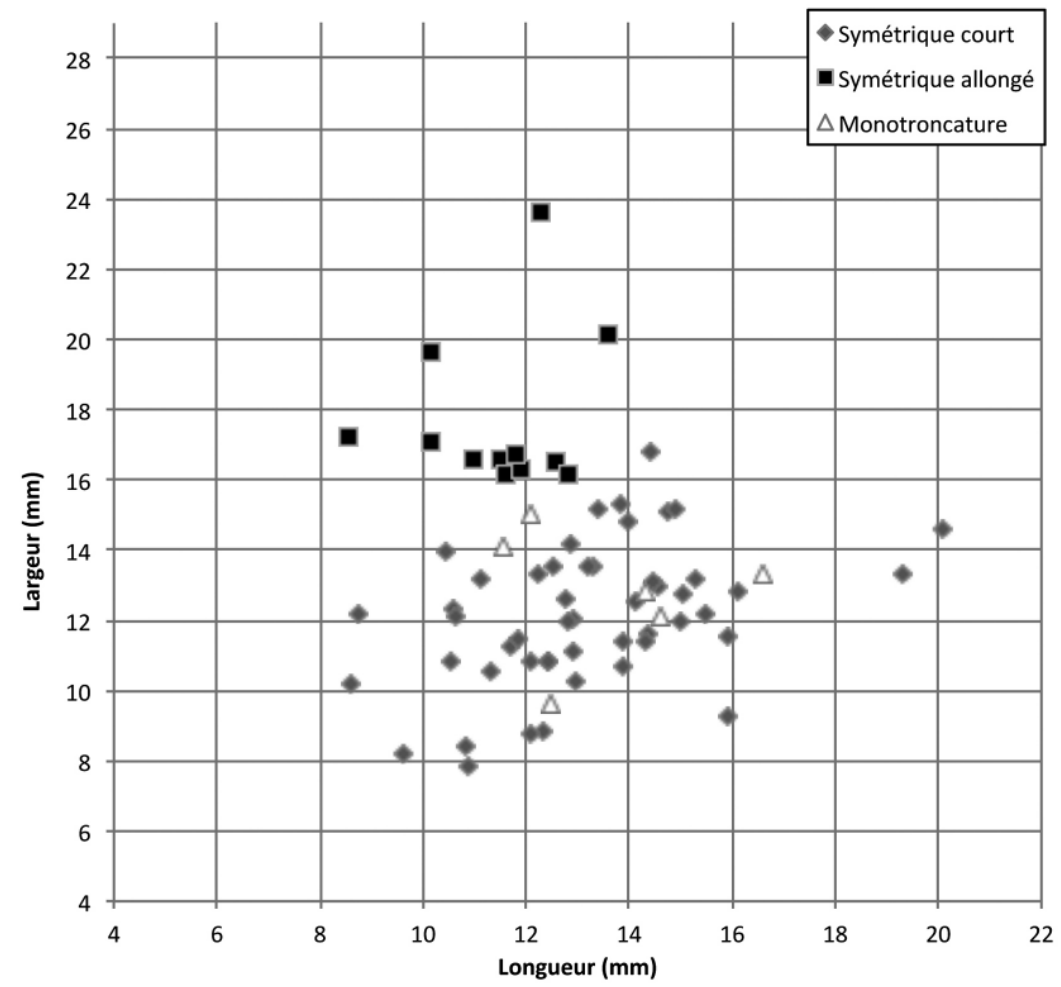


Figure 16 : Longueur (grande base) et petite base des bitroncatures symétriques et des monotroncatures (surface et sondages).

Figure 16 : Length (big base) and width (small base) of the symmetric bitroncations and the monotruncations (excavations and surface finds).

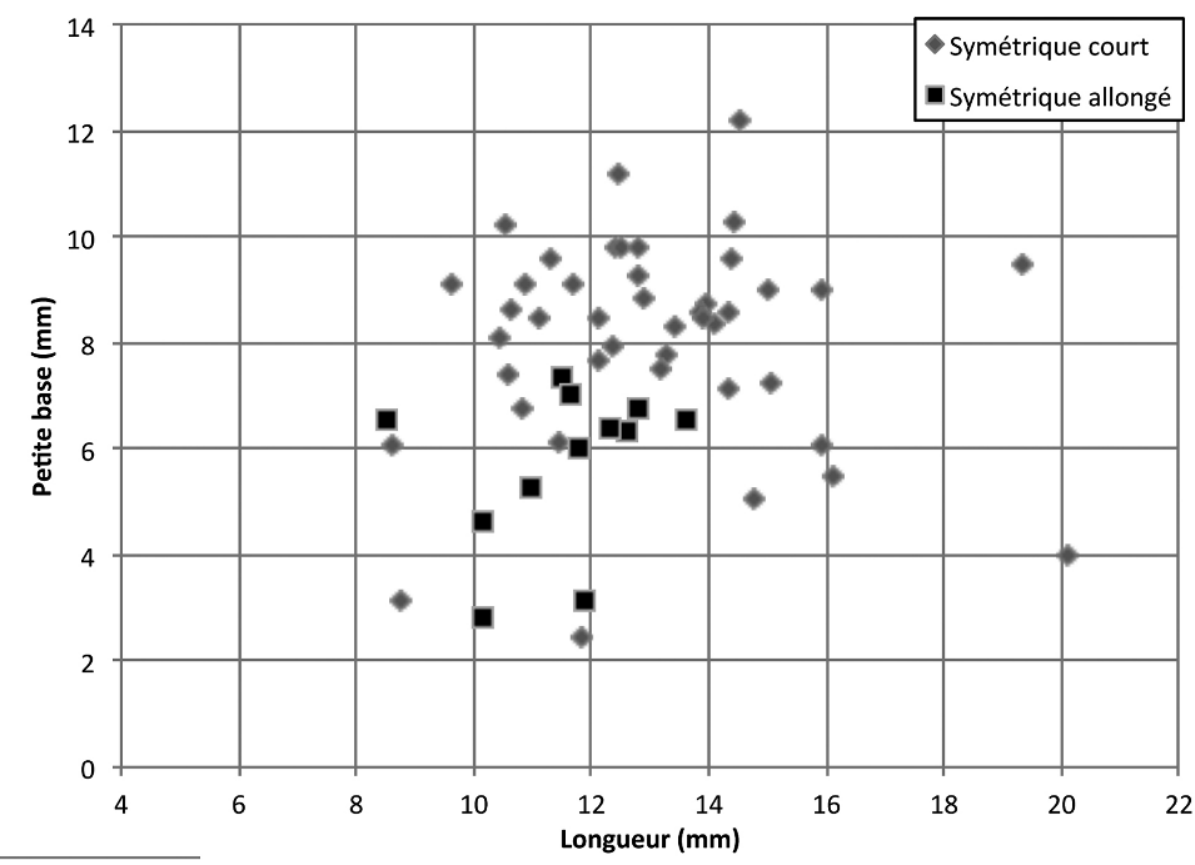

Figure 17 : Largeur et petite base des bitroncatures symétriques et des monotroncatures (surface et sondages).

Figure 17: Width and width (small base) of the symmetric bitroncations and the monotruncations (excavations and surface finds).

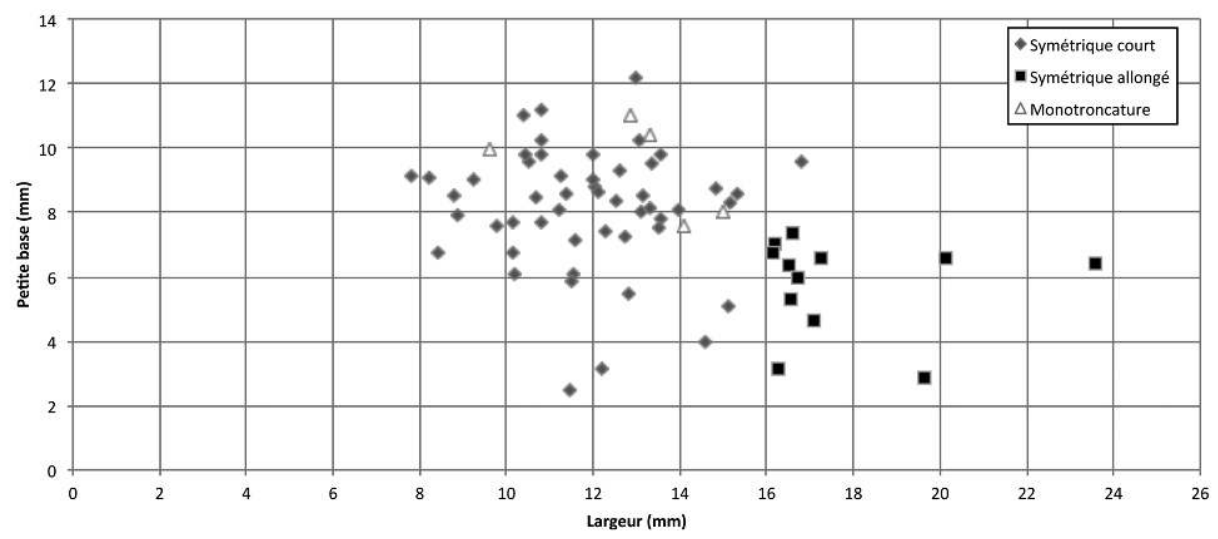

Il y a donc de manière claire deux sous-types de bitroncatures, les deux ayant fonctionné en flèches tranchantes. Il est intéressant de noter que la proportion de pièces chauffées après la taille est plus importante parmi les armatures que dans l'ensemble du mobilier des sondages: $30,4 \%$ des bitroncatures des sondages sont affectées contre $19 \%$ du reste du mobilier (seulement $6 \%$ des armatures en surface, mais les pièces les plus abîmées ont sans doute été inconsciemment écartées des ramassages).

Les autres armatures sont anecdotiques. On notera dans le sondage E (carré 1, US 1) un triangle scalène de très petites dimensions (fig. $11, n^{\circ} 24$ ), réalisé par une petite troncature directe rectiligne et une grande troncature convexe; un petit bordage en 
partie apicale vient renforcer la pointe. Long de 10,7 millimètres pour 4,2 millimètres de large, ce triangle apparaît bien solitaire sur le site, malgré le tamisage à l'eau. En surface, il faut également signaler la présence de deux segments de dix-huit et vingttrois millimètres de long. Ces trois objets ne sont pas absents des répertoires typologiques armoricains, mais ils ne sont pas très caractéristiques d'une période particulière. Le premier appelle toutefois des comparaisons avec le premier Mésolithique. Pour les seconds, il est étonnant de les voir apparaître ici, comme d'ailleurs dans les grands corpus d'armatures régionaux (Beg-er-Vil, Téviec, Hoëdic), où ils apparaissent toujours à une ou deux unités.

\section{Le macro-outillage}

Les outils massifs découverts dans les sondages sont au nombre de sept, accompagnés de cinq fragments (tableau 1). Dans le sondage D (carré 1, US 2), on note un galet en granite qui a servi d'enclume, à la fois de manière passive sur ses faces et de manière active à ses extrémités, mais avec, dans tous les cas, des stigmates très peu marqués (fig. $9, \mathrm{n}^{\circ} 1$ ). Dans le sondage $\mathrm{D}$, hélas sur le tas de déblais à cause d'une erreur de fouille, fut découverte une molette circulaire en quartz filonien (qui porte encore des restes de micaschiste incrusté) à section en biseau (fig. $9, \mathrm{n}^{\circ} 2$ ). Contrairement à l'enclume en granite, son attribution au Mésolithique est impossible. Dans le sondage A (US 2), une plaque de micaschiste roulée par les flots a été grossièrement percutée sur ses bords pour en faire un objet très grossièrement quadrangulaire (enlèvements alternants mais pas sur enclume). Elle mesure 90 millimètres de long pour 74 millimètres de large et 13 millimètres d'épaisseur. Dans le sondage C (US 2), un galet en roche vert foncé à inclusions de quartz a été biseauté à une extrémité par l'usage et porte des stries sur les bords de manière rayonnante, qui semblent être des traces d'outils coupants, l'objet fonctionnant alors comme une sorte d'enclume. Il mesure trente-neuf millimètres de long pour vingt-quatre millimètres de large et treize millimètres d'épaisseur : des études complémentaires doivent être entreprises pour en déterminer le fonctionnement.

Le vallon a offert quelques autres macro-outils. Dans le sondage B (US 2), il y avait un fragment de meule en granite de section semi-ovalaire. On rappellera que cette roche est absente du socle et a été importée depuis Houat ou depuis le continent. Une grosse boucharde en quartz filonien gisait dans l'US 3 du sondage F (carré 3), travaillée sur son pourtour et sur une face, dont la masse atteint 652 grammes (longueur $95 \mathrm{~mm}$ ). Un percuteur sur galet de quartz de petites dimensions a été recueilli dans la même US (longueur 44,9 mm). Plus bas dans l'US 4, on note un autre percuteur sur galet de quartz, assez trapu, qui porte des marques d'impact assez ténues (longueur: $66 \mathrm{~mm}$, largeur : $59 \mathrm{~mm}$, épaisseur : $38 \mathrm{~mm}$ ). Faute de traces d'usage à sa surface, on ne mettra pas dans la catégorie du macro-outillage un gros galet de grès verdâtre long de 180 millimètres, découvert au sommet de l'US 4, soit dans la même position stratigraphique qu'un nucléus mésolithique (fig.6). Un transport par l'homme fut cependant nécessaire à son arrivée à cet endroit.

\section{Complément d'enquête : le mobilier de surface issu de la cuvette}

45 Le matériel lithique récolté par G. Musch est estimé à plus de dix mille pièces. Cet assemblage impressionnant a fait l'objet d'un tri pour séparer les différents outils des 
restes de débitage, puis d'une pesée pour donner une idée de leurs proportions respectives (fig. 18). À l'examen des vingt kilos de silex taillés, aucun élément intrus n'est apparu, notamment aucune pièce attribuable au Néolithique comme des grattoirs circulaires ou des perçoirs fusiformes. Le cas des dix bitroncatures symétriques allongées, examiné plus haut, est à l'évidence ambigu car ces armatures sont en continuité morphologiques avec les pièces de plus petites dimensions. De même que pour le mobilier issu des sondages, il apparaît que seules les roches disponibles sur l'île ont été débitées et, notamment, les galets de silex glanés sur le littoral. Il s'agit de très petits nodules, rendus gélifs par une exposition à des conditions périglaciaires, qui n'autorisent pas une production de supports allongés. Les galets de grès-quartzite et de quartz ont été débités, mais en moindres proportions (respectivement $2400 \mathrm{~g}$ et $250 \mathrm{~g}$ ).

Figure 18 : Proportions en poids de différentes catégories de l'assemblage lithique recueilli en surface par G. Musch.

Figure 18: Proportions (weight) of various categories of lithic industry finding on the field by G. Musch.

Industrie en silex taillé recueillie en surface $(20 \mathrm{~kg})$

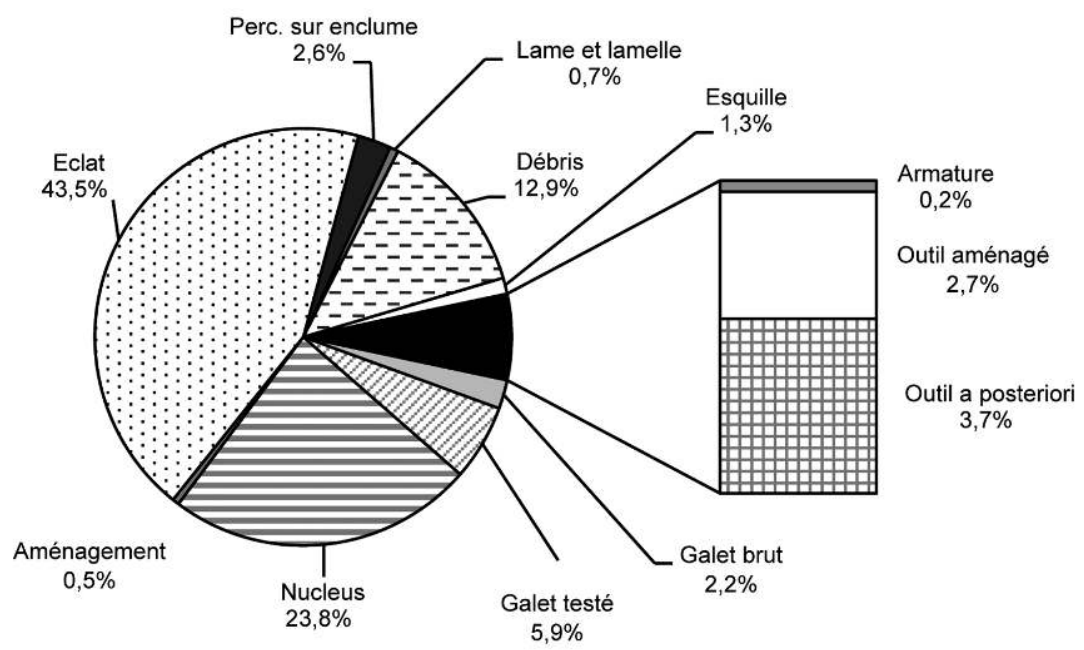

Décompte G. Marchand en quartz d'un module similaire à ceux des outils trouvés en sondages. Nous avons dessiné ici (fig. 8) un denticulé sur éclat en quartzite, assimilable à un chopper fait par des enlèvements inverses, qui est un des outils les plus caractérisés de la série de surface. Sa pointe est cassée et un des bords bruts a servi pour une percussion lancée peu développée. Il a été utilisé également en percussion sur des matières minérales à un "angle " naturel, si on en croit les traces d'impact, mais il n'est pas possible de préciser si c'était avant ou après le débitage de l'éclat support.

Pour le silex, plusieurs méthodes de débitage ont été détectées, toutes réalisées à la percussion directe dure. Le débitage par percussion bipolaire sur enclume est représenté, mais il ne semble intervenir qu'entre des phases de débitage direct pour venir à bout de certaines résistances des matériaux. Les armatures sont exclusivement des bitroncatures trapézoïdales symétriques (utilisées en flèches tranchantes). Le reste 
de l'outillage comprend des perçoirs réalisés par des troncatures concaves sur des éclats épais irréguliers et des éclats denticulés. On note quelques éclats ou courtes lames à coches scalariformes, de type lame « Montbani ». Il convient de s'attarder un peu sur les quatre couteaux entiers et un fragment (fig. 19), qui sont des outils très caractéristiques de cette phase chronologique au même titre que les bitroncatures symétriques. Ils sont réalisés sur des supports allongés et assez réguliers, des éclats plutôt que des lames. La troncature est franchement convexe, mais elle ne concerne pas la totalité du bord, dont la partie proximale peut être laissée brute. La pointe est en extrémité distale et la latéralisation peut-être à gauche (3) ou à droite (1). Les retouches d'aménagement du bord sont directes et, dans deux cas, abruptes, croisées à proximité de la pointe. Il s'agit d'objets courts, bien dans l'esprit du reste de l'assemblage lithique : les longueurs sont comprises entre 45 millimètres et 35 millimètres, pour des largeurs d'environ 20 millimètres et des épaisseurs comprises entre 6 et 10 millimètres. L'une des pièces (fig. $19, \mathrm{n}^{\circ} 2$ ) a d'ailleurs été amincie par de grands éclats inverses, tirés à partir du dos, signe peut-être qu'elle devait être insérée dans un manche préalablement fabriqué. Il n'y a guère de doute sur le fait que le tranchant de ces couteaux a été très utilisé, tandis que les pointes ne sont pas des perçoirs.

Figure 19: Couteaux à dos recueillis en surface.

Figure 19 : Backed knifes.

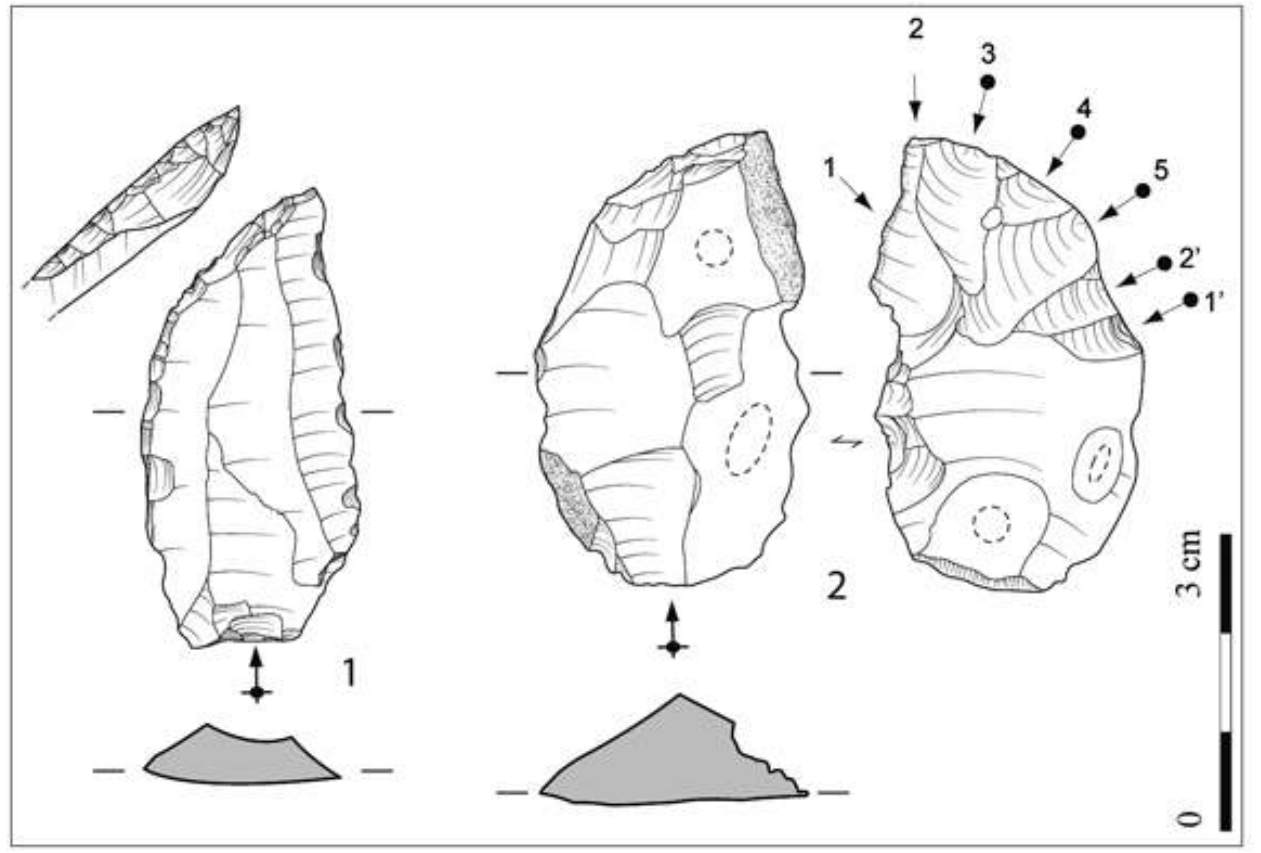

Dessins G. Marchand

\section{Comparaisons régionales et proposition de datation}

\section{Jalons chronologiques du Téviecien}

Dénommée Téviecien par J.-G. Rozoy (1978), l'entité technique et stylistique décrite tant à Hoëdic qu'à Téviec occupe les actuels départements du Finistère et du Morbihan. Elle représente la déclinaison régionale des industries à lames régulières et trapèzes qui forment, en Europe occidentale, le second Mésolithique. Les fouilles de P. Gouletquer, 
O. Kayser, G. Marchand et Y. Pailler depuis 1970 ont notablement accru les assemblages lithiques de référence et par rebond le corpus des dates par le radiocarbone (une quarantaine actuellement). Si l'on connaît désormais plus d'une soixantaine de sites rattachables à cette entité technique, quelques-uns apparaissent comme des piliers incontournables de nos connaissances. Le niveau coquillier de Beg-er-Vil à Quiberon (Morbihan) vient démarrer ce cycle, avec des dates comprises entre 6200 et 6000 avant notre ère et une domination quasi-totale des bitroncatures symétriques parmi les armatures, qui définit le faciès Beg-er-Vil (Marchand, 2005a, 2012). On notera à cette période la présence des couteaux à dos, tandis que ce sont les lames à troncature oblique qui seront développées ultérieurement. Il est dans l'immédiat impossible de comprendre les liens avec les phases antérieures, sinon un rapport général avec le Gildasien connu en Loire-Atlantique mais assez mal daté dans la première moitié du VII ${ }^{\mathrm{e}}$ millénaire (Dupont et al., 2007).

Beg-an-Dorchenn à Plomeur (Finistère) est un autre jalon téviecien bien calé autour de 5700-5500 avant notre ère, qui voit une concurrence des bitroncatures symétriques par les armatures asymétriques (trapèzes et triangles larges) à hauteur de $30 \%$. Les deux autres grands sites à niveaux coquilliers du Morbihan - Téviec à Saint-Pierre-Quiberon et Port-Neuf à Hoëdic - ont été fouillés anciennement (Péquart et al., 1937, 1954) et leur mobilier n'est que partiellement préservé ; qui plus est, les dates par le radiocarbone obtenues sur ossements humains dans les années 2000 posent de nombreux problèmes de calibration liées à l'effet réservoir océanique (Marchand et al., 2009). Si la nécropole de Hoëdic est occupée semble-t-il longuement et ne sert pas ici notre propos typochronologique, les dates de Téviec semblent se concentrer autour de 5300 avant notre ère. Les armatures asymétriques y semblent encore davantage représentées qu'à Began-Dorchenn, cette signature définissant le faciès Hoëdic. Il serait donc postérieur au faciès Beg-er-Vil, contrairement à ce que l'on pensait après les travaux d'O. Kayser (1992). Les dates obtenues sur les sites de Kerliézoc (Plouvien ; Josselin et al., 2003) et de Pont-Glas (Marchand et Le Goffic, 2009) viennent compliquer un peu les perspectives, puisque des assemblages à bitroncatures symétriques du faciès Beg-er-Vil sont respectivement datés de 5500-5300 et 5400-5300 avant notre ère. Les contextes sédimentaires sont cependant moins assurés qu'à Beg-er-Vil et il est probablement trop tôt pour bâtir un modèle d'évolution du contenu des carquois. Si la dynamique d'évolution typologique proposée par O. Kayser (1992) doit désormais être inversée radicalement, aucun nouveau modèle linéaire ne peut plus être proposé à l'échelle régionale dans l'immédiat pour rendre compte des changements d'armatures.

\section{Insertion de Bordelann dans cette entité technique}

50 Même si le contexte sédimentaire du mobilier lithique recueilli à Bordelann est bien déficient, nous pointerons plusieurs paramètres qui en font un ensemble important et par certains aspects assez original pour le Mésolithique de l'Ouest de la France :

1. La cohérence de la série en dépit des conditions sédimentaires déplorables;

2. L'importance quantitative de la série lithique et la densité des pièces au mètre carré ;

3. La rareté des séquences laminaires et lamellaires ;

4. La méthode de production unipolaire d'éclats minces par recul frontal de séquences courtes ;

5. La domination sans partage des bitroncatures symétriques parmi l'outillage ; 
6. La présence en surface de couteaux à dos ;

7. L'absence d'hyper-microlithe ;

8. La très grande rareté des outils aménagés et l'abondance des armatures.

51 Point 1. Il serait hors de propos de traiter ce site mésolithique d'homogène stricto sensu. Les huit petits tessons découverts dans les sondages à l'emplacement de la cuvette, qui plus est à la base des sédiments, nous signalent en effet un passage au Néolithique ou à la protohistoire. Les bitroncatures symétriques allongées sont assimilables à des flèches tranchantes du Néolithique moyen, mais on en connaît aussi trois exemplaires de mêmes dimensions dans le second Mésolithique de Beg-er-Vil. Cependant, la grande rareté du débitage bipolaire sur enclume, l'unique enclume - d'ailleurs peu marquée et l'absence de grattoirs et de perçoirs nous conduit à minorer ces intrusions postérieures. Cette cohérence - pour éviter la notion d'homogénéité - est relativement rare pour un site de cette superficie, qui plus est bouleversé par l'érosion, et elle ne peut s'expliquer que par l'absence d'intérêt manifesté après le Mésolithique pour une zone sans attrait topographique particulier, au contraire des alentours immédiats de la source. Il faut peut-être imaginer au Mésolithique un couvert végétal particulier, une clairière, qui aurait incité les hommes et les femmes à revenir plusieurs fois à cet endroit.

52 Point 2. Avec 430 pièces au mètre carré dans le sondage $\mathrm{D}$, Bordelann montre une densité remarquable de pièces lithiques. Pour mémoire, on peut rappeler quelques autres moyennes obtenues en Finistère, dans de semblables conditions stratigraphiques dégradées et avec de mêmes modalités d'intervention (sondages manuels depuis la surface, incluant donc le labour, tamisage à l'eau): 205 pièces à la Villeneuve (Locunolé), 80 à la Trinité-Goarem-Lann (Melgven), 103 à Kerliézoc (Plouvien) et seulement 14 à Kerdunvel (Plourin-Ploudalmézeau) (Josselin et al., 2003 ; Marchand, 2005b). Dans tous les cas toutefois, les intenses prospections de surface préalables aux sondages avaient évidemment appauvri les récoltes ultérieures lors des fouilles. Par comparaison aux autres, le site de Bordelann est peu étendu, l'image qui doit rester est donc celle d'une accumulation importante de mobilier en un point précis quoique anodin du paysage.

53 Point 3. La rareté des séquences laminaires et lamellaires fait écho à ce que l'on avait observé à Beg-er-Vil au siècle dernier (Marchand, 1999). Il n'y a avait sur ce site que $7 \%$ de nucléus à table lamellaire, $8 \%$ de lamelles et $4,3 \%$ de lames (débitage brut). Leurs proportions étaient nettement plus fortes parmi les armatures et les outils communs. La collection de Bordelann semble bien correspondre totalement à ces orientations de la production. La sollicitation de ces supports allongés est alors intense pour la confection de l'outillage, comme on le constate pour les armatures.

Point 4. La méthode de débitage semble être une version simplifiée de celle observée à Beg-an-Dorchenn et identique à celle connue à Beg-er-Vil (Marchand, 1999). Mais sur ces deux sites, nos observations récentes révèlent un usage de la percussion indirecte pour l'obtention de supports réguliers, ce qui n'est pas le cas ici.

Points 5 et 6. La domination quasi-totale des bitroncatures symétriques à Bordelann permet une assimilation au Téviecien de faciès Beg-er-Vil, d'autant plus que les couteaux à dos sont présents exclusivement dans les deux cas. En l'état des connaissances, il s'agit donc de la plus ancienne phase des industries à lames régulières et trapèzes en Bretagne à la fin du VII millénaire, mais que l'on rencontre aussi en 
centre-Finistère au milieu du $\mathrm{VI}^{\mathrm{e}}$ millénaire dans des contextes stratigraphiques moins assurés. Le site éponyme est sur la commune de Quiberon, à dix-sept kilomètres au nord-est de Bordelann sur le continent (Marchand, 1999), on en usera donc comme de la comparaison la plus aisée et légitime.

Point 7. L'absence d'hyper-microlithe hormis le petit triangle scalène est un point important à signaler, encore une fois comme sur les autres sites de la région. Se pose alors la question du lien entre le Téviecien et des groupes du premier Mésolithique qui utilisaient ces types d'armatures effilées. On calque de fait ces interrogations sur de semblables questionnements abordés dans le Sud de la France, où le passage du Montclusien à triangles très effilés aux premières industries à trapèzes (tous symétriques) semble brutal. Mais il nous manque bien des jalons en Bretagne entre le premier et le second Mésolithique; la nature exacte de ces assemblages anciens en Morbihan est très conjecturale, pour tous les millénaires précédents le VII ${ }^{\mathrm{e}}$ millénaire.

Point 8. La proportion des armatures au sein de l'outillage aménagé est de $75 \%$ dans le sondage $\mathrm{D}$ et de $100 \%$ dans le sondage E. Par comparaison avec d'autres chiffres obtenus sur des sites de l'Ouest de la France, il s'agit de taux très importants, dont le mobilier récolté en surface donnait déjà le pressentiment. Sur de telles bases, on distinguera d'ailleurs les niveaux coquilliers d'autres types de stations occupées plus brièvement (Marchand, 2000, 2012). Sur les premiers, comme Beg-er-Vil ou Beg-anDorchenn, les armatures comptent respectivement pour $50 \%$ et $46,8 \%$ de l'outillage aménagé. Dans l'abri sous roche de Pont-Glas (Plounéour-Ménez, Finistère) en revanche, les armatures sont en plus forte proportion (67,7\%), tandis que sur le petit site de sommet de falaise de la Gilardière à Pornic (Loire-Atlantique) - attribué lui au Reztien - les armatures comptaient pour $75 \%$ des outils aménagés. La très grande rareté des outils aménagés, et en corollaire l'abondance des armatures, pourraient introduire une divergence avec Beg-er-Vil, où parmi les 5884 pièces (dont 422 esquilles), on identifiait quand même quelques éclats denticulés et quelques grattoirs : est-ce un effet du mode de prélèvement ? Peut-être. Dans le cas contraire, on aurait une différence fonctionnelle intéressante à approfondir pour comprendre la raison de la venue de ces hommes et ces femmes sur cette île. Il ne faut pas non plus oublier, dans cette discussion sur le statut fonctionnel du site, une certaine rareté du macro-outillage à Bordelann, si l'on excepte les galets de quartz impliqués dans les activités de percussion directe liées probablement au débitage.

\section{Un habitat de chasseurs-cueilleurs en contexte insulaire}

\section{Les chasseurs-cueilleurs marins}

Par un effet de balancier si commun dans la recherche académique, le Mésolithique côtier de Bretagne est de nouveau sous le feu des projecteurs, après plusieurs années de travaux concentrés sur les nombreux habitats de l'hinterland. Cette attention accrue s'appuie sur un nouvel énoncé des problématiques, emprunté pour partie à des auteurs comme D. Yesner (1980), L. Binford (2001) ou R. Kelly (2007), mais elle est liée également à des travaux de laboratoire dans l'Ouest qui sont venus démontrer la dichotomie entre les zones littorales et continentales (Dupont et al., 2009 ; Marchand, 2012). Pour des peuples vivant de prédation, il est clair que la prodigalité des écosystèmes marins et leur renouvellement perpétuel par le jeu des marées confèrent un fort potentiel nutritif à ces zones, avec un étalement des ressources protéiques dans 
l'année qui permet de compléter les proies terrestres. Mais cette observation reste fort générale et bien des paramètres vont influer sur la nature réelle des économies mises en œuvre aux différentes latitudes et des formes sociales afférentes, en premier lieu évidemment, la richesse réelle des biomasses secondaires et les modes de vie des proies exploitées. Les observations ethnographiques réalisées à des latitudes similaires à celles de l'Europe atlantique montrent que les peuples exploitant certains milieux marins ont bénéficié de conditions optimales pour développer des économies de prédation particulières au sein de sociétés souvent qualifiées de "complexes " (Price et Brown, 1985 ; Rowley-Conwy, 2004). Leurs caractères définis à partir de peuples de chasseurscueilleurs du Nord-Ouest de l'Amérique du Nord et du Japon comprennent notamment une sédentarité liée à l'organisation logistique de la prédation, de fortes densités démographiques, un degré significatif de territorialité et une défense des ressources qui s'exprime parfois par des conflits armés (Yesner, 1980). Des structures sociales d'ordinaire associées aux sociétés agro-pastorales y sont aussi signalées, avec des hiérarchies sociales affirmées, une compétition entre les individus ou les lignages et parfois même le développement de l'esclavage. Les chercheurs signalent comme conditions initiales la haute richesse de la biomasse, la diversité des ressources, la stabilité écologique de l'environnement marin par rapport aux environnements terrestres à semblables latitudes et la forte proportion d'espèces migratrices susceptibles d'être capturées ensemble. Le stockage des ressources halieutiques est alors au centre des pratiques économiques de ces peuples; de cette anticipation collective peuvent naître en effet diverses formes sociales de contrôle des stocks, plus ou moins centralisées (Testart, 1982). Tous les peuples exploitant des milieux maritimes n'ont pourtant pas développé ces caractères techniques ou de telles sociétés à rangs, ainsi des indiens Yamana (ou Yahgan) ou des Alakalouf en Terre de Feu (extrême sud de l'Argentine et du Chili), dont l'alimentation était basée aux trois quarts sur les ressources halieutiques (Kelly, 2007, p. 67) et qui avaient une organisation sociale basée sur l'unité familiale (Legoupil, 2000).

C'est l'objectif des nouveaux travaux entrepris sur les niveaux coquilliers que de définir avec davantage de précision la richesse de cet environnement et notamment sa variabilité saisonnière qui donnait le tempo de la mobilité humaine. La fouille de Bordelann n'a cependant livré que des informations "minérales", qui ne peuvent abonder que des questionnements sur les différents types d'habitats composant les réseaux économiques mésolithiques.

\section{Le système littoral dans le Morbihan à la fin du Mésolithique}

60 Une typologie sommaire des différents types d'habitats mésolithiques sur le littoral du sud de la Bretagne montre des différences bien marquées (tableau 8). Il apparaît cependant que les différentes occupations repérées sur le littoral continental ou sur les îles sont similaires. On ajoutera d'ailleurs qu'aucune signature typologique ou technologique originale n'a été perçue entre les assemblages lithiques de ces zones. Une navigation régulière est une hypothèse nécessaire pour rendre compte de cette homogénéité culturelle qui ne permet pas de distinguer de particularismes insulaires. Se pose évidemment la question des moyens de navigation: le Mésolithique n'a livré que des pirogues monoxyles en pin ou en tilleul, dans la Seine ou la Baltique. Ces embarcations allongées étaient-elles adaptées à des traversées marines assez longues et à la houle atlantique ? L'aspect technique est un autre problème ; le seul gros outillage 
susceptible d'être impliqué dans leur creusement, même en supposant un dégrossissage préalable par le feu, serait les haches en bois de cerf découvertes à Téviec et à Hoëdic. Il faudrait réaliser des expérimentations adaptées, et pour la fabrication et pour la navigation, pour identifier les contraintes contournées par les gens du Mésolithique. Pour conclure sur ce point, nous avons la démonstration indirecte d'une navigation relativement régulière entre les îles et le continent - il n'y a pas d'isolat culturel - mais le volet technique nous échappe encore totalement.

Tableau 8 : Classement des habitats tévieciens dans le Nord-Ouest de la France (fin VIle et Vle millénaire avant notre ère), selon leur position sur la bande littorale ou sur une île.

Table 8 : Teviecians habitats.

\begin{tabular}{|c|c|c|c|c|c|}
\hline $\begin{array}{l}\text { Ensemble } \\
\text { géographique }\end{array}$ & $\begin{array}{l}\text { Type de } \\
\text { site }\end{array}$ & Exemple & Implantation & $\begin{array}{l}\text { Structure } \\
\text { archéologique }\end{array}$ & Outillage \\
\hline \multirow[t]{4}{*}{ Bande littorale } & $\begin{array}{l}\text { Niveau } \\
\text { coquillier à } \\
\text { nécropole }\end{array}$ & Téviec & $\begin{array}{l}\text { Trait de côte - } \\
\text { Petite falaise }\end{array}$ & $\begin{array}{l}\text { Foyers empierrés, } \\
\text { tombes, } \\
\text { cénotaphe, aire } \\
\text { dallée }\end{array}$ & Équilibré \\
\hline & $\begin{array}{l}\text { Niveau } \\
\text { coquillier } \\
\text { sans } \\
\text { nécropole }\end{array}$ & $\begin{array}{l}\text { Beg-er-Vil, } \\
\text { Beg-an- } \\
\text { Dorchenn }\end{array}$ & $\begin{array}{l}\text { Trait de côte - } \\
\text { Petite falaise }\end{array}$ & $\begin{array}{l}\text { Aire dallée, fosses, } \\
\text { foyers non } \\
\text { appareillés }\end{array}$ & Équilibré \\
\hline & $\begin{array}{ll}\text { Station de } \\
\text { sommet de } \\
\text { falaise }\end{array}$ & $\begin{array}{l}\text { Pors-Bali, } \\
\text { Porz-Carn }\end{array}$ & $\begin{array}{l}\text { Trait de côte - } \\
\text { Falaise }\end{array}$ & Inconnue & $\begin{array}{l}\text { Production } \\
\text { de lamelles - } \\
\text { Armatures }\end{array}$ \\
\hline & $\begin{array}{l}\text { Plein-air } \\
\text { intérieur }\end{array}$ & Ty-Nancien & & Inconnue & \\
\hline \multirow[t]{3}{*}{ Île } & $\begin{array}{l}\text { Niveau } \\
\text { coquillier à } \\
\text { nécropole }\end{array}$ & Hoëdic & $\begin{array}{l}\text { Trait de côte - } \\
\text { Petite falaise }\end{array}$ & $\begin{array}{l}\text { Foyers, tombes, } \\
\text { cénotaphe, aire } \\
\text { dallée }\end{array}$ & Équilibré \\
\hline & Plein-air & Bordelann & $\begin{array}{l}\text { Bord de plateau, } \\
\text { au-dessus d'un } \\
\text { vallon encaissé et } \\
\text { d'un ruisseau }\end{array}$ & Inconnu & Armatures \\
\hline & Plein-air & Roc'h Gored & $\begin{array}{l}\text { Trait de côte - } \\
\text { Falaise }\end{array}$ & Inconnu & Inconnu \\
\hline
\end{tabular}

61 Ces singularités insulaires vont-elles se loger dans un registre davantage fonctionnel? Existe-t-il des habitats spécialisés particuliers nécessitant des outils spécifiques? Les analyses tracéologiques sur les tranchants d'outils en silex sont encore anecdotiques sur les assemblages décrits ici. Dans l'immédiat, on ne peut aborder la question des fonctions des sites que par de grossiers indicateurs : proportions des différents outils aménagés, taux de pièces altérées par le feu, nature des structures archéologiques (Marchand, 2000, 2012). Bordelann trancherait sur d'autres sites littoraux par la forte 
domination des armatures, qui indiquerait plutôt une station logistique dévolue à des activités de prédation. Par ailleurs, la proportion de pièces brûlées y est un peu moindre que sur d'autres sites de Bretagne, ce qui est cohérent avec des sites où la durée d'occupation est courte (Marchand, 2000). Sur ces deux seuls paramètres, on pourrait émettre l'hypothèse de stations logistiques répétées, les amas coquilliers à aménagements lourds livrant moins d'armatures et un plus fort taux de pièces altérées par le feu. On pourra ajouter dans la discussion la rareté de l'outillage de gros calibre à Bordelann, alors qu'il abonde dans les amas coquilliers, en lien dans ce cas avec une plus grande variété des activités quotidiennes. Mais comment concilier cette première conclusion avec l'abondance du mobilier qui nous éloigne de la notion de campement de chasse ? Seule une récurrence des occupations serait à même d'engendrer une telle abondance de pièces, à condition d'ailleurs que le statut du site ne change pas entre les passages humains... Voilà beaucoup d'hypothèses! Et ce n'est pas une nouvelle fouille plus étendue qui viendra nous éclairer, puisque les conditions sédimentaires sont si médiocres, mais plutôt la multiplication des sites fouillés qui aideront à trouver d'autres éléments de contrastes entre habitats.

Pourquoi installer un campement à un tel endroit? Bordelann est en retrait d'un demikilomètre du littoral, mais reste directement confronté aux rudes conditions écologiques de la côte sauvage. On note deux paramètres importants qui ont dû influer dans les choix : l'existence vers l'ouest d'un accès aisé au vallon et donc à la mer et, le plus important, la présence à quelques dizaines de mètres à l'est d'une source pérenne aujourd'hui très abondante. En revanche, rien ne conditionne l'implantation d'un campement à cet endroit précis sur la pente et non pas ailleurs autour de la source, sinon les traditions de ce peuple préhistorique et peut-être la protection de boisements particuliers aujourd'hui insaisissables. La question de l'épuisement des ressources en mammifères terrestres a été posée plus haut, qui fait des îles des espaces écologiques fragiles et pas forcément adaptés à des économies de chasse prospères. Il est possible que ce soit plutôt des ressources marines disponibles sur la côte extérieure qui auront entraîné hommes et femmes à revenir à cet endroit. Pourrait-il alors s'agir des phoques dont on sait qu'ils furent consommés à Téviec ou à Beg-er-Vil ? Une question essentielle qui restera hélas sans réponse...

Les habitats à nécropoles et à déchets marins abondants, comme Téviec et Hoëdic, sont peut-être au centre de cette mobilité collective par voie maritime. Le second site est bien entendu le parangon de l'occupation insulaire mésolithique depuis les fouilles des années 1930 (Péquart et al., 1954). La préservation des ossements dans ce niveau carbonaté nous permet aujourd'hui de considérer la variété des proies terrestres (sangliers, chevreuils, cerfs, renards et aurochs). On ne sait pas quelles parties des animaux étaient présentes, en quelles quantités et si toutes ces chasses étaient réalisées à proximité : on peut avoir de sérieux doutes pour l'aurochs ou le cerf, qui réclament de grands espaces. Même si l'île actuelle était reliée à l'époque à Houat (Buttin, 2009; Menier et al., 2010), il n'est pas évident que tous ces animaux s'ébattaient à l'époque sur d'aussi faibles superficies. Quoi qu'il en soit, le niveau archéologique est décrit par les fouilleurs comme très pauvre en restes fauniques terrestres et, d'ailleurs, c'est dans cette nécropole que les taux de nourriture marine atteignent les $80 \%$, d'après les analyses isotopiques des ossements humains (Schulting et Richards, 2001). Ce site insulaire servait-il d'habitat résidentiel à partir duquel partaient des expéditions lointaines, notamment sur les îles, ou bien était-il un relais lors des cycles de 
déplacement fréquent de tout le groupe ? La lourdeur des aménagements, dont une aire empierrée qui évoque une habitation, est plutôt caractéristique de stationnements humains prolongés, de même évidemment que les sept sépultures connues. Ces grands sites à niveau coquillier seraient plutôt des pivots de l'espace social, des lieux fortement marqués dans le territoire, où s'associaient morts et vivants et où les lignées familiales trouvaient à s'affirmer, en parfait contraste avec des sites comme Bordelann.

D'autres types de stations manquent à l'appel dans un système d'exploitation des ressources littorales qui demandera encore beaucoup de travaux pour être bien compris, que ce soit les sites de boucherie, les pêcheries ou encore les petites stations de chasse/pêche. L'érosion marine a détruit nombre de ces traces archéologiques, notamment dans les zones les plus basses; sur le continent la pression anthropique très forte sur le littoral est venue ajouter ses effets délétères pour entraver encore davantage notre projet, même si des îlots de savoirs subsistent miraculeusement comme le niveau coquiller de Beg-er-Vil. Les destructions humaines furent moins fortes sur les îles du Morbihan et cela autorise bien des espoirs, comme la découverte récente par P. Crevat de l'abri sous roche de Valenpaul dans les falaises de Locmaria en est l'augure. Même très dégradés comme l'est Bordelann, les sites mésolithiques insulaires ont beaucoup à nous apprendre sur l'exploitation de milieux naturels contraints. Il faudra probablement établir une hiérarchie de ces espaces si particuliers, le plateau vaste et élevé de Belle-île ne pouvant se comparer à des espaces plus restreints comme l'île aux Moutons ou même Hoëdic. À l'échelle de cette île, nos travaux d'inventaire et de prospections battent leur plein, afin de continuer à traiter la question des chasseurscueilleurs marins dans toutes ses dimensions; nul doute alors que les résultats même modestes obtenus à Bordelann irrigueront les modèles développés à l'avenir en Bretagne sur le fonctionnement des systèmes d'exploitation littoraux.

Nous remercions vivement S. Perinelle et F. Perinelle, propriétaires de la parcelle et G. Huel, son exploitant, de nous avoir permis d'intervenir en ces lieux. Nous remercions S. Deschamps et $\mathrm{Y}$. Rumégoux, du service régional de l'archéologie de Bretagne, pour nous avoir autorisés à sonder sur le site de Bordelann avec les moyens idoines, de même que E. Bernard pour lequel nous avons une pensée émue. Merci à L. Quesnel pour la réalisation de certaines figures de cet article. Un grand merci bien évidemment aux fouilleurs qui ont participé à cette opération archéologique : J.-P. Agosta, L. Aubertin, L. Audouard, J.-M. Cardeilhac, M. Castille, C. Guéret, J.-C. Le Blay, P. Lesayec, L. Quesnel et $\mathrm{E}$. Werthe. Notre gratitude va enfin à $\mathrm{C}$. Andrieu pour la révision du résumé en langue anglaise, ainsi qu'à $\mathrm{F}$. Séara et T. Perrin pour leurs corrections et remarques sur une première version de ce manuscrit.

\section{BIBLIOGRAPHIE}

AUDOUARD L., BARRACAND G., TARAUd t. et muSch G., 2010 - « Belle-Île-en-Mer du Mésolithique à l'âge du Bronze : émergence d'une nouvelle dynamique de recherche », Bulletin de l'AMARAI, 23, p. 17-26. 
ватт м. et кAYSER 0., 1989 - « Prospection archéologique à Belle-Île-en-Mer (56) », Bulletin de l'AMARAI, 2, p. 21-25.

BINFORD L. R., 2001 - Constructing Frames of reference.An analytical method for archaeological theory building using ethnographic and environmental data sets, Berkeley, University of California Press, 563 p.

BUTTIN P., 2009 - « Niveaux marins et géographie de l'archipel Houat-Hoëdic », Melvan, la revue des deux îles, 6, p. 9-25.

DUPont c., 2006- La malacofaune de sites mésolithiques et néolithiques de la façade atlantique de la France: contribution à l'économie et à l'identité culturelle des groupes concernés, Oxford, Archeopress, British Archaeological Reports, International Series 1571, 439 p.

DUPONT C., MARCHAND G., GRUET Y. et TESSIER M., 2007 - « Les occupations mésolithiques de la Pointe SaintGildas (Préfailles, Loire-Atlantique) dans leur cadre paléoenvironnemental », Gallia Préhistoire, 49, p. 161-196.

DUPONT C., TRESSET A., DESSE-BERSET N., GRUET Y., MARCHAND g. et sCHULting R., 2009 - « Harvesting the seashores in the Late Mesolithic of north-western Europe. A view from Brittany? », Journal of World Prehistory, 22/2, p. 93-111.

DUPONT C., MARCHAND G., CARRION Y., DESSE-BERSET N., GAUDIN L., GRUET Y., MARGUERIE D. et OBERLIN C., 2010 - « Beg-anDorchenn : une fenêtre ouverte sur l'exploitation du littoral par les peuples mésolithiques du $\mathrm{VI}^{\mathrm{e}}$ millénaire dans l'Ouest de la France », Bulletin de la Société préhistorique française, 107, 2, p. 227-290.

GUYODO J.-N. et MARCHAND G., 2005 - « La percussion bipolaire sur enclume dans l'Ouest de la France de la fin du Paléolithique au Chalcolithique : une lecture économique et sociale », Bulletin de la Société préhistorique française, t. 102, 3, p. 539-550.

Josselin J., MARchand G., PAILleR y., MOALIC L., hamon G. et leroy A., 2003 - Kerliézoc en Plouvien (Finistère). « Regards croisés sur un habitat du Mésolithique final », Revue archéologique de l'Ouest, 20, p. 53-85.

KAYSER 0., 1992- « Les industries lithiques de la fin du Mésolithique en Armorique, in LE RouX C.-T.

(dir.), Paysans et Bâtisseurs. L'émergence du Néolithique atlantique et les origines du Mégalithisme, Actes $\mathrm{du} 17^{\mathrm{e}}$ colloque interrégional sur le Néolithique, Vannes, 29-31 octobre 1990, Revue archéologique de l'Ouest, supplément $n^{\circ}$ 5, p. 117-124.

KеLLY R., 2007 - The foraging spectrum. Diversity in Hunter-Gatherer lifeways, New York, Percheron Press, $446 \mathrm{p}$.

LEGoUPIL D., 2000 - « L'adaptation en milieux froids des chasseurs-cueilleurs de Patagonie et de Terre de Feu : des contraintes aux stratégies ", in CUPILLARD c. et RICHARD A. (dir.), Les Derniers chasseurscueilleurs d'Europe occidentale (13000-5500 av. J.-C.), Besançon, 351-360.

MARCHAND G., 1999 - « La néolithisation de l'Ouest de la France : caractérisation des industries lithiques », British Archaeological Reports, International Series 748, 487 p.

MARCHAND G., 2000 - « Facteurs de variabilité des systèmes techniques lithiques au Mésolithique récent et final dans l'Ouest de la France ", in скотті P. Meso'97. Table-ronde sur l'Épipaléolithique et le Mésolithique, Lausanne, novembre 1997, p. 37-48.

MARCHAND G., 2003 - «Les niveaux coquilliers du Mésolithique final en Bretagne : fonctionnement des habitats côtiers et intégration territoriale ", Préhistoire Anthropologie méditerranéenne, 12, p. 209-219. 
MARCHAND G., 2005a - « Le Mésolithique final en Bretagne : une combinaison des faits archéologiques ", in MARCHAND G. et TRESSET A. (dir.), Unité et diversité des processus de néolithisation sur la façade atlantique de l'Europe (VII-IV millénaires av. J.-C.), Paris, Société préhistorique française, mémoire 36, p. 67-86.

MARCHAND G., 2005b - « Les occupations mésolithiques à l'intérieur du Finistère. Bilan archéographique et méthodologique (2001-2003) », Revue archéologique de l'Ouest, 22, p. 25-84. MARCHAND G., 2012 - Préhistoire atlantique. Fonctionnement et évolution des sociétés du Paléolithique au Néolithique, Mémoire d'habilitation à diriger les recherches, université de Rennes 1, 406 p. MARChAND G.et TSOBGou-AHoupe R., 2007 - « Comprendre la diffusion des roches au Mésolithique en Bretagne : analyse structurale des matériaux et variabilité technique », Archéosciences, 31, p. 113-126.

MARCHAND G. et LE GOFFIC M., 2009 - « Give us some small sites please! Report on the first year of excavations in the rock shelter of Pont-Glas (Plouneour-Menez, Finistère, France) », Mesolithic Miscellany, 19, 2, p. 12-16.

MARCHAND G., DUPONT C., OBERLiN c. et DelQUE-KOLIC E., 2009 - « Entre "effet réservoir" et "effet de plateau" : la difficile datation du Mésolithique de Bretagne ", in CROMBÉ P., VAN STRYDONCK M., SERGANT J., BATS M.et Boudin M. (dir.), Proceedings of the international congress "Chronology and Evolution in the Mesolithic of NW Europe", Cambridge Scholar Publishing, p. 307-335.

MENIER D., 2004 - Morphologie et remplissage des vallées fossiles sud-armoricaines : apport de la stratigraphie sismique, Doctorat de l'université de Bretagne Sud, Mémoires Géosciences Rennes, 110, 202 p.

MENIER D., SCALLIET F., PROUST J.N. et CASSEN S., 2009 - « Contexte géomorphologique et paléoenvironnemental en Bretagne Sud au Pléistocène ", in CASSEN S. (dir.), Autour de la Table. Explorations archéologiques et discours savants sur des architectures néolithiques - La fabrique du temps et des surfaces, p. 796-809.

MENIER D., TESSIER B., PROUST J.-N., BALTZER A., sORREL P. et TRAINI C., 2010- « The Holocene transgression as recorded by incised-valley infilling in a rocky coast context with low sediment supply (southern Brittany, western France) ", Bulletin de la société géologique française, 181, 2, p. 115-128.

MORZADEC-KERFOURN M.-T., 1974 - Variation de la ligne de rivage armoricaine au Quaternaire, Mémoire de la Société géologique et minière de Bretagne, 17, 208 p.

péQuart M. et s.J., Boule M. et vallois, H., 1937 - Téviec, station nécropole mésolithique du Morbihan, Archives de l'Institut de Paléontologie Humaine, mémoire 18, Paris, 227 p.

PÉQUART M. et s.J., 1954 - Hoëdic. Deuxième station-nécropole du Mésolithique côtier armoricain, De Sikkel, Anvers, $93 \mathrm{p}$.

PIRAzzoli P. A., 1991 - « World atlas of Holocene sea level changes », Oceanography Series, 58, Amsterdam, Elsevier, 300 p.

PRICE T. D. et BRown J. A., 1985 - « Aspects of Hunter-Gatherer Complexity », in PRICE T. D. et BRoWn J. A. (dir.), Prehistoric hunter-gatherers: the emergence of cultural complexity, Academic Press, New York, p. 3-20. Rowley-ConWYP., 2004- « Complexity in the Mesolithic of the Atlantic Façade: Development or adaptation? », in GONZÁLEZ MORALES M. et CLARK G. A. (dir.), The Mesolithic of the Atlantic façade : proceedings of the Santander Symposium, Arizona State University, Anthropological Research Papers, 55, p. 1-12. 
Rozoy J-G., 1978 - «Les derniers chasseurs. L'Épipaléolithique en France et en Belgique », Bulletin de la Société archéologique champenoise, $\mathrm{n}^{\circ}$ spécial juin 1978, 605 p, 259 pl.

SCHULTING R. J. et RICHARDS M. P., 2001 - « Dating women becoming farmers: new paleodietary and AMS dating evidence from the breton mesolithic cemeteries of Téviec and Hoëdic ", Journal of Anthropological Archaeology, 20, p. 314-344.

SCHULting R., TRESSET A. et DUPONT C., 2004 - « From Harvesting the Sea to Stock Rearing Along the Atlantic Façade of North-Western Europe », Environmental Archaeology, 9, p. 143-154.

séLosse M.-A., 2000 - « Histoire récente et façonnement géologique de Belle-île », Penn ar Bed « Homme et nature à Belle-île », 176-177, p. 13-24.

SORRELP., TESSIER B., DEMORY F., BALTZER A., BOUAOUINA F., PROUST J.-N., MENIER D. et TRAINI C., 2010 - « Sedimentary archives of the French Atlantic coast (inner Bay of Vilaine, south Brittany): depositional history and late Holocene climatic and environmental signals ", Continental Shelf Research, 30, p. $1250-1266$.

TESTART A., 1982 - Les chasseurs-cueilleurs ou l'origine des inégalités, Société d'Ethnographie. Paris, 254 p. TRESSET A., 2002 - « De la mer au bétail en domaine atlantique : unité et diversité des processus d'apparition de l'élevage à la marge nord-ouest de l'Europe ", Antropozoologica, 36, p. 13-35.

TRESSET A., 2005 - «L'avifaune des sites mésolithiques et néolithiques de Bretagne (5500 à 2500 av. J.C.) : implications ethnologiques et biogéographiques ", Revue de Paléobiologie, Genève, vol. spécial, 10, p. 83-94.

YESNERD., 1980 - « Maritime Hunter-Gatherers: Ecology and Prehistory », Current Anthropology, 21, 6, p. $727-750$.

\section{RÉSUMÉS}

Découvert en 2004 par G. Musch, le site mésolithique de Bordelann sur la commune de Sauzon (Morbihan, France) est très vite apparu comme le plus important assemblage de cette période sur l'île de Belle-Île-en-Mer. Les milliers de silex découverts à proximité d'une source pérenne sur la pente d'un vallon de la côte ouest témoignaient d'un campement humain de longue durée, sur une surface relativement restreinte (2 $200 \mathrm{~m}^{2}$ environ). Dans le cadre d'un programme de recherche sur le fonctionnement des sociétés mésolithiques de l'Ouest de la France, nous avons entrepris son exploration pour illustrer plus particulièrement le système économique très particulier des chasseurs-cueilleurs maritimes dans les espaces insulaires. En 2009, une série de carottages à la tarière nous avait permis de prendre connaissance d'un état géomorphologique de la parcelle, montrant à l'occasion la différence entre, d'une part, une zone à vestiges mésolithiques à la faible couverture sédimentaire sur une pente et, d'autre part, les flancs d'un petit vallon recélant d'épais dépôts organiques. Neuf sondages manuels furent ensuite réalisés en 2011 pour une surface totale de trente-deux mètres carrés. L'érosion intense de la première zone se traduit par un nappage continu de colluvions probablement récentes. Le tamisage à l'eau systématique nous a permis de démontrer que le mobilier lithique recueilli est très abondant (4000 pièces). Il est composé notamment d'esquilles et de petits éclats, avec une fraction lamellaire congrue. Les armatures sont presque toutes des bitroncatures symétriques trapézoïdales, dont une étude vétilleuse est proposée. L'outillage aménagé du fonds commun est anodin. Ce mobilier très homogène est identique à celui issu du niveau coquillier Beg-er-Vil à Quiberon, bien daté de l'intervalle 6200-6000 avant notre ère. Quelques tessons de petites 
dimensions dénoncent un passage à la protohistoire. Cette dernière période est nettement mieux représentée et préservée dans le vallon près de la source, où les dépôts atteignent 1,30 mètre d'épaisseur. Protégé par des colluvions épaisses, un niveau noir très organique d'une cinquantaine de centimètres avait enregistré un possible passage gallo-romain à son sommet, une occupation du second âge du Fer en son milieu et une occupation à la base plus difficile à dater (Néolithique ou protohistoire). Il ne s'agit pourtant que d'occupations très périphériques liées à l'usage de la source.

Malgré ces évidentes limites sédimentaires, ce site reste fondamental pour la fin du Mésolithique à l'échelle régionale, comme un exemple encore unique de vaste habitat insulaire sans amas coquillier à la différence de Hoëdic. Ses occupants entretenaient à l'évidence des liens directs avec Beg-er-Vil et les habitats continentaux, ce qui éclaire davantage les réseaux économiques de cette période où le système de chasse-cueillette établi sur le littoral apparaît comme si original, avec une hiérarchisation des fonctions que l'on peut déjà entrevoir.

Since its discovery in 2004 by G. Musch, the Mesolithic site of Bordelann at Sauzon (island of Belle-île-en-Mer, Morbihan, France) appeared as one of the most important sites of this period for the island. The presence of thousands of flints discovered near a permanent well on the slope of a valley on the west coast indicated the presence of a long-term human camp that was settled in a relatively small area (2200 $\mathrm{m}^{2}$ more or less). We decided to begin its exploration in order to understand the very specific economic system of the maritime hunters-gatherers in the island areas. Such work took place within the framework of a research program on the organization of Mesolithic societies in the western France. In 2009, a series of core drillings on the site allowed us to understand the geomorphologic context of the site and showed us a very clear difference between a zone that contained Mesolithic lithic pieces on a slope and another one, on the sides of a small valley, that contained thick organic deposits but quite rare archaeological remains. Nine trial trenches were then dug manually in 2011 on a total surface of $32 \mathrm{~m}^{2}$. The main Mesolithic zone appeared to be have been disturbed by recent colluviums, but we collected a lot of lithic material (4000 pieces) thanks to the systematic use of water sieving. This lithic collection was mostly composed of flakes, blades and bladelets being really rare. The arrowheads are all symmetric trapezes which have been the object of a detailed study for this paper. The rest of the tools are relatively scarce. Interestingly, this very homogeneous assemblage is identical to the one found in the Beg-er-Vil (Quiberon), a shell-midden that is well dated to $6200-6000 \mathrm{Cal} \mathrm{BC}$ interval. A few ceramic sherds also indicate an Iron Age occupation. However this last period is far better represented and preserved in the valley near the spring, where the silt and clays deposits are $1.30 \mathrm{~m}$ thick. There, protected by thick colluviums, a very organic black level of about fifty centimetres contained a possible Gallo-Roman level on its summit, as well as an Iron Age occupation in its middle, and a much more difficult to qualify occupation (Neolithic or Protohistoric) on the bottom. All these levels correspond however to very secondary occupations that were probably only related to the use of the spring at these different time periods.

Despite of these obvious sedimentary limits, this site remains important for the understanding of the end of the Mesolithic at a regional scale. As a matter of fact it is a unique example of a vast island settlement with no shell-midden unlike that of Hoëdic. Its prehistoric inhabitants obviously maintained direct links with Beg-er-Vil and the continental settlements. This data clearly enlightens the economic networks of this period, when the system of hunting-gathering established on the coast appears to be very original, with a hierarchical organization of the functions within each site which we can already glimpse.

Descubierto en 2004 por G. Musch, el sitio mesolítico del municipio de Bordelann en el pueblo de Sauzon (Morbihan, Francia) se ha convertido rápidamente en el mayor montaje que se conoce de 
este periodo en la isla de Belle-Ile-en-Mer. Los miles de sílex encontrados cerca de una fuente en la ladera de un valle en la costa oeste testimonian de un campamento humano de largo plazo en una área relativamente pequeña $\left(2.200 \mathrm{~m}^{2}\right)$. En el cuadro de un programa de investigación sobre el funcionamiento de las sociedades del Mesolítico del oeste de Francia, hemos comenzado a estudiar el conjunto para ilustrar más particularmente el sistema económico de los cazadoresrecolectores marítimos de las zonas insulares. En 2009, una serie de extracciones nos permitió conocer el estado geomorfológico de la trama, mostrando en esta ocasión la diferencia entre, por una parte, una zona con vestigios mesolíticos con débil cubierta sedimentaria en una ladera y, por otra parte, las pistas de un pequeño valle que tenía gruesos depósitos orgánicos. Entonces, nueve estudios manuales se llevaron a cabo en 2011 para una superficie total de treinta y dos metros cuadrados. La fuerte erosión de la primera zona se traduce por una cubierta continua de colluvial probablemente reciente. El cribado sistemático por medio de agua nos ha permitido demostrar que la lítica conseguida es muy abundante (4.000 unidades). Está hecha especialmente de astillas y pequeñas explosiones, con una fracción laminar congruente. Los marcos son casi todos bi truncamientos simétricos trapezoidales de los que se propone un estudio meticuloso. Las herramientas integradas del fondo común son insignificantes. Este mobiliario muy homogéneo es idéntico al que se extrajo de Beg-er-Vil en Quiberon, y que data con certidumbre del intervalo situado entre 6200 y 6000 antes de nuestra época. Algunos fragmentos de pequeña dimensión demuestran un pasaje a la época protohistórica. Este período es mucho mejor representado y conservado en el valle, cerca de la fuente, donde los depósitos alcanzan 1,30 metros de espesor. Protegido por un coluvial grueso, un nivel negro muy orgánico de unos cincuenta centímetros registró un posible pasaje galo-romano en su parte superior, una ocupación de la segunda Edad del Hierro en el centro y una ocupación más difícil de determinar en la base (Neolítico o protohistoria). Sin embargo, se revelaron ocupaciones periféricas relacionadas con el uso de la fuente.

A pesar de estos límites sedimentarios obvios, este sitio tiene una importancia fundamental para finales del Mesolítico al nivel regional y constituye un ejemplo único de un largo hábitat sin grupos de cascaras a la diferencia de Hoëdic. Sus ocupantes mantenían obviamente algunos vínculos directos con Beg-er-Vil y los hábitats continentales, lo que aclara mejor sobre las redes económicas de este período en el que el sistema de caza y recolección establecido en la costa aparece como original, con una jerarquización de las funciones que ya se puede vislumbrar.

\section{INDEX}

Keywords : Belle-Île-en-Mer, Brittany, Mesolithic, Teviecian, Lithic industry

Palabras claves : Belle-île-en-Mer, Bretaña, Mesolítico, Téviecien, industria lítica

Mots-clés : Belle-Île-en-Mer, Bretagne, Mésolithique, Téviecien, industrie lithique

\section{AUTEURS}

\section{GRÉGOR MARCHAND}

UMR 6566 du CNRS - CREAAH - Laboratoire Archéo-sciences - Bâtiment 24-25 - Université de Rennes 1 - CS74205 - 35042 RENNES Cedex (gregor.marchand@univ-rennes1.fr ).

\section{GÉRALD MUSCH}

Gérald Musch - Rue Charles-de-la-Touche, 56360 Le Palais (biemasso@yahoo.fr ). 